\title{
Excitotoxic Activation of the NMDA Receptor Results in Inhibition of Calcium/Calmodulin Kinase II Activity in Cultured Hippocampal Neurons
}

\author{
Severn B. Churn, David Limbrick, Sompong Sombati, and Robert J. DeLorenzo \\ Department of Neurology, Medical College of Virginia, Richmond, Virginia 23298
}

Neurotoxic effects of excitatory amino acids have been implicated in various neurological disorders, and have been utilized for excitotoxic models of delayed neuronal cell death. The excitotoxic glutamate-induced, delayed neuronal cell death also results in inhibition of calcium/calmodulin-dependent kinase II (CaM kinase II). In this report, we characterized the glutamate-induced inhibition of CaM kinase II in relation to loss of intracellular calcium regulation and delayed neuronal cell death. Glutamate (500 $\mu \mathrm{m}$ for 10 min), but not $\mathrm{KCl}(50 \mathrm{~mm})$, exposure resulted in a significant inhibition of CaM kinase II activity. The inhibition of CaM kinase II activity was observed immediately following excitotoxic glutamate exposure and present at every time point measured. Glutamate-induced inhibition of kinase activity and delayed neuronal cell death was dependent upon both the activation of the NMDA glutamate receptor subtype and the presence of extracellular calcium. The relationship between inhibition of CaM kinase II activity and loss of intracellular calcium regulation was also examined. Experimental conditions which resulted in significant neuronal cell death and inhibition of CaM kinase II activity also resulted in a long-term loss of intracellular calcium regulation. Thus, inhibition of CaM kinase II activity occurred under experimental conditions which resulted in loss of neuronal viability and loss of neuronal calcium regulation. Since the glutamate-induced inhibition of CaM kinase II activity preceded neuronal cell death, the data support the hypothesis that inhibition of CaM kinase II activity may play a significant role in excitotoxicity-dependent, delayed neuronal cell death.

[Key words: excitotoxicity, cell culture, calcium, phosphorylation, glutamate cations, pharmacology]

Neurotoxic effects of excitatory amino acids have been implicated in various neurological disorders and have becn utilized for excitotoxic models of delayed neuronal cell death (Rothman, 1986; Choi and Rothman, 1990; Choi, 1992). Glutamate-induced, delayed neuronal excitotoxicity has been shown to be

\footnotetext{
Received Mar. 25, 1994; revised Oct. 18, 1994; accepted Nov. 10, 1994.

This work was supported by an NINDS Jacob Javits award (R01-NS23350) and Epilepsy Program Project (PO1-NS25630) to R.J.D., NIH Postdoctoral Grant (HL07537) to S.B.C., and the Sophie and Nathan Gumenick Neuroscience and Alzheimer Research Fund. We thank Adam M. Gray for his expert technical assistance on the Syntide II assays.

Correspondence should be addressed to Severn B. Churn, Ph.D., Department of Neurology, Medical College of Virginia, Box 599 MCV Station, Richmond, VA 23298.

Copyright (C) 1995 Society for Neuroscience $0270-6474 / 95 / 153200-15 \$ 05.00 / 0$
}

dependent on activation of the NMDA subtype of glutamate receptors (Choi et al., 1988; Koh and Choi, 1991) and has been correlated with incrcascd intraccllular calcium levels (Connor et al., 1988; Glaum et al., 1990; Wadman and Connor, 1992; Hartley et al., 1993). In addition, removal of extracellular calcium from the culture media during glutamate exposure has a beneficial effect on neuron survival (Choi, 1987; Choi et al., 1988; Michaels and Rothman, 1990; Choi and Hartley, 1993). Therefore, alteration of neuronal calcium physiology may be a major mechanism by which glutamate exposure induces cell death.

The multifunctional $\mathrm{Ca}^{2+} /$ calmodulin-dependent protein $\mathrm{ki}$ nase II (CaM kinase II) is a major $\mathrm{Ca}^{2+}$ second messenger system that regulates many $\mathrm{Ca}^{2+}$-dependent processes in neurons (Jameson et al., 1980; Caroni and Carafoli, 1983; Goldenring et al., 1984a; Yamamoto et al., 1985; Sakakibara et al., 1986; Baskys et al., 1990; Amador and Dani, 1991; McGlade-McGulloh et al., 1993). CaM kinase II phosphorylates and regulates the function of receptor-gated ion channels (McGlade-McGulloh et al., 1993; Machu et al., 1993), neuroskeleton elements (DeLorenzo et al., 1982), calcium-dependent ion channels (Sakakibara et al., 1986; Baskys et al., 1990) and is involved in neurotransmission (DeLorenzo, 1981; DeLorenzo, 1983; Llinas et al., 1985). CaM kinase II comprises $1 \%$ of total forebrain protein and up to $2 \%$ of total hippocampal protein (Goldenring et al., 1983; Kennedy et.al., 1983b; Ouimet et al., 1984; Erondu and Kennedy, 1985; Schulman, 1989). In addition, CaM kinase II is predominantly expressed in neurons relative to glial cells (Erondu and Kennedy, 1985; Schulman, 1989; Churn et al., 1992b). The $\alpha$-subunit is homologous to the major postsynaptic density protein (PSD) which comprises up to $50 \%$ of the total PSD protein (Kennedy et al., 1983a; Goldenring et al., 1984b; Kelly et al., 1984). The high synaptic expression of CaM kinase II suggests that this enzyme may be important for normal synaptic function. Since CaM kinase II is a neuronally enriched enzyme that regulates many important cellular processes, inhibition of this important enzyme system would have important effects on neuronal function.

Significant inhibition of CaM kinase II activity has been observed in many models of delayed neuronal cell death including whole animal models of ischemia (Taft et al., 1988; Churn et al., 1990b, 1992a; Zivin et al., 1991; Aronowski et al., 1992) and glutamate excitotoxicity in neuronal cultures (Churn et al., 1993). Transient forebrain ischemia results in greater than $50 \%$ inhibition of CaM kinase II activity in hippocampus (Taft ct al., 1988; Churn et al., 1990b) and cortex (Churn et al., 1990b). The decrease in CaM kinase II activity observed after ischemia is an early (within $10 \mathrm{sec}$ ) and long-lasting phenomenon that precedes 
the development of delayed neuronal cell death (Taft et al., 1988; Churn et al., 1990b). This inhibition of CaM kinase II activity has been implicated in contributing to delayed neuronal cell death by several laboratories (Taft et al., 1988; Zivin et al., 1991; Aronowski et al., 1992; Churn et al., 1993). Therefore, understanding the cellular mechanisms involved in regulating the inhibition of CaM kinase II would provide insight into the molecular mechanisms of excitotoxicity induced changes in neuronal transducing systems.

In this report, primary hippocampal neuronal cultures were utilized to characterize the effects of excitotoxic glutamate exposure on delayed cell death, alteration of internal free calcium regulation and inhibition of $\mathrm{CaM}$ kinase II activity. The data indicate that excitotoxic glutamate exposure resulted in a significant inhibition of CaM kinase II activity and that the observed inhibition of this enzyme is NMDA receptor mediated. Inhibition of CaM kinase II activity occurred immediately following glutamate exposure and persisted until delayed neuronal cell death occurred. In addition, inhibition of CaM kinase II activity was dependent on extracellular calcium and could be prevented by omission of calcium from the culture medium. The data support the hypothesis that inhibition of CaM kinase II activity may be involved in calcium-dependent, delayed neuronal cell death.

\section{Materials and Methods}

\section{Hippocampal cell culture}

Primary hippocampal cultures were prepared by a modification of the method of Banker and Cowan (1977) as described by Sombati et al. (1991). Briefly, hippocampal cells were prepared from $2 \mathrm{~d}$ postnatal rats (Harlan) and grown on a confluent hippocampal astroglial feeder layer. Astrocytes were prepared from $2 \mathrm{~d}$ old pups by the methods of Abney et al., (1981). The glial cultures were maintained for 2 weeks in the 60 $\mathrm{mm}$ dishes (Costar) and fed twice weekly with MEM, $10 \%$ fetal bovine serum, and $2 \mathrm{mM}$ L-glutamine, $10 \mathrm{~mm}$ glucose. After confluence (approximately $4 \mathrm{~d}$ ), the glial cultures were exposed to $5 \mu \mathrm{M}$ cytosine arabinoside to inhibit further proliferation. The day prior to neuronal plating, the glial feed was replaced with $\mathrm{N}_{3}$-supplemented neuronal feed. The $\mathrm{N}_{3}$ supplement contained 25 mM HEPES buffer ( $\left.\mathrm{pH} 7.4\right), 2$ mM glutamine, $5 \mu \mathrm{g} / \mathrm{ml}$ insulin, $100 \mu \mathrm{g} / \mathrm{ml}$ transferrin, $100 \mu \mathrm{M}$ putrescine, $30 \mu \mathrm{M}$ sodium selenite, $20 \mu \mathrm{m}$ progesterone, $1 \mathrm{~mm}$ sodium pyruvate, $0.1 \%$ ovalbumin, $20 \mu \mathrm{g} / \mathrm{ml} \mathrm{T}_{3}, 40 \mu \mathrm{g} / \mathrm{ml}$ corticosterone. Hippocampal cells were plated at a density of $7.5 \times 10^{5}$ cells $/ 60 \mathrm{~mm}$ culture dish onto a confluent glial bed. Cultures were maintained at $37^{\circ} \mathrm{C}$ under $5 \% \mathrm{CO}_{2}, 95 \%$ air. Cultures were fed three feedings/week ( $1 / 2$ half media change) with $\mathrm{N}_{3}$-supplemented, Earle's Salt's containing minimum essential medium (MEM). The glutamine, MEM and HEPES buffer were obtained from GIBCO (Gaithersburg, MD). All other culture reagents were obtained from Sigma Chemical Co. (St. Louis), except where specified.

\section{Neurotoxicity assays}

Under sterile conditions, neuronal feed was replaced with three complete changes of recording solution. Careful changes of the culture medium were performed to minimize trauma to cultured neurons and prevent drying of culture beds. All changes were performed under a sterile hood by slow suction removal of old medium with simultaneous, slow application of new medium. Recording solution contained (in $\mathrm{mM}$ ) $\mathrm{NaCl}, 145 ; \mathrm{KCl}, 2.5 ; \mathrm{CaCl}_{2}, 1 \mathrm{MgCl}_{2}$, 1; D-glucose, 10; Na-HEPES, 10; glycine, $0.01 ; \mathrm{pH} 7.3$. The osmolarity was adjusted to $325 \mathrm{mOsm}$ with sucrose. Recording solution was replaced with recording solution containing $500 \mu \mathrm{M}$ glutamate (or $100 \mu \mathrm{M}$ NMDA) and $10 \mu \mathrm{M}$ glycine for $10 \mathrm{~min}$. Glutamate toxicity was also contrasted with $50 \mathrm{~mm} \mathrm{KCl} \mathrm{ex-}$ posure (Glaum et al., 1990). Cultures were washed by three complete changes of recording solution (no drug). Neuronal feed was replaced and neurons allowed to recover for $3 \mathrm{~d}$ under the normal feeding schedule. Viable cells were identified as phase-bright cells with intact processes (Churn et al., 1993). Nonviable neurons appeared phase dark and contained crenelated neuritic processes. In some experiments, trypan blue exclusion was used to determine neuronal viability. Surviving cells are expressed as percent viable cells remaining from original counts.

\section{CaM kinase II assays}

Under sterile conditions, culture medium was replaced with recording solution as described above. Following experimental treatment, cultures were washed three times with recording solution and two times with culture medium. Neuronal cultures were allowed to recover in neuronal feed for specified times at $37^{\circ} \mathrm{C}$, and isolated for quantitation of kinase activity. For quantitation of CaM kinase II activity, hippocampal neurons were washed twice with recording solution at $37^{\circ} \mathrm{C}$. The wash solution was rapidly replaced with ice-cold homogenization buffer $(100$ $\mathrm{mM}$ piperazine- $N, N^{\prime}$-bis[2(-ethane sulfonic acid)] (PIPES) $\mathrm{pH} 6.9,1 \mathrm{~mm}$ ethylenediamine-tetra-acetic acid (EDTA), $2 \mathrm{~mm}$ [ethylenebis(oxyethylenenitrilo)] tetra-acetic acid (EGTA), $0.3 \mathrm{~mm}$ phenylmethylsulfonyl fluoride), and the cells were immediately scraped from the culture dish surface. The suspension was transferred into a glass homogenizer (Kontes, Vineland, NJ), and disrupted as described previously (Churn et al., 1992a) as modified in (Churn et al., 1993). Homogenates were normalized for protein and studied for endogenous calcium-dependent protein phosphorylation. Standard phosphorylation reaction solutions contained $41 \mu \mathrm{g}$ of protein, $10 \mathrm{~mm} \mathrm{MgCl}, 7 \mu \mathrm{M} \gamma-{ }^{32} \mathrm{P}$ ATP, $10 \mathrm{~mm}$ PIPES $\mathrm{pH} 7.4, \pm 5 \mathrm{mM} \mathrm{CaCl}_{2}$ and $\pm 600 \mu \mathrm{M}$ calmodulin. The concentration of free calcium was estimated with a $\mathrm{Ca}^{2+} /$ EGTA buffer system (Portzehl et al., 1964) as described in Burke and DeLorenzo (1981). The standard free $\mathrm{Ca}^{2+}$ concentration for maximal activity was $50 \mu \mathrm{M}$. Final reaction volume was $100 \mu \mathrm{l}$. Standard reactions were performed in a shaking water bath at $30^{\circ} \mathrm{C}$. Reactions were initiated by the addition of calcium, continued for $1 \mathrm{~min}$, and terminated by the addition of $5 \%$ sodium dodecyl sulfate (SDS) STOP solution (Churn et al., 1992a). Proteins were resolved by sodium dodecyl sulfate-polyacrylamide gel electrophoresis (SDS-PAGE) and protein bands visualized as described previously (Churn et al., 1992a). Stained gels were dried and exposed to X-ray film (XRP-1, Kodak) for autoradiography. CaM kinase II subunits were identified by running purified kinase fractions in parallel gel lanes as described (Churn et al., 1990a, 1992a,b; 1993). The CaM kinase II subunits were further identified by Western analysis (see below) of autophosphorylated protein using a monoclonal antibodies against the $\beta$ subunit (Churn et al., 1992b) or the $\alpha$ subunit (Boehringer Mannheim. Indianapolis) of CaM kinase II. The autoradiograph was then used as a template for excising radioactive phosphoproteins for quantitation in a liquid scintillation spectrometer (model LS 2800, Beckman), with a counting efficiency of $80 \%$ (Churn et al., 1990a, 1992a). In some experiments, computer-assisted densitometry was utilized (Mocha, Jandel Corp., San Rafael, CA), as previously described (Churn et al., 1992a). Inhibition of CaM kinase II activity was analyzed by one-way ANOVA (Graphpad, San Diego, CA).

\section{Phosphocellulose assay of CaM kinase II phosphorylation of Syntide II}

Substrate phosphorylation was performed by a modification of the method of Hashimoto and Soderling (1987). For kinase activity, standard reactions were performed as described above, except that $60 \mu \mathrm{M}$ Syntide II (Sigma, St. Louis) was included in the mixture. This concentration of Syntide II was found to provide maximal phosphate incorporation under standard conditions (see Fig. 8). The phosphorylation reaction was initiated by the addition of $\mathrm{Ca}^{2+}$, allowed to continue for $1 \mathrm{~min}$ and stopped by the addition of $20 \mathrm{~mm}$ EDTA; $10 \mu \mathrm{l}$ of the assay solution was immediately blotted onto phosphocellulose filter paper, P-81 (Whatman, Maidstone, England) as described previously (Hashimoto and Soderling, 1987). Each reaction was quantitated in triplicate. P-81 filter paper was then washed three times in $50 \mathrm{~mm}$ phosphoric acid, rinsed with acetone, and allowed to air dry. Radioactive phosphate was quantitated by scintillation counting as described above.

\section{Phosphatase studies}

To determine the phosphatase activity towards CaM kinase II, removal of phosphate from the $\alpha$ subunit of CaM kinase II was measured as described previously (Churn et al., 1992a). Control CaM kinase II was phosphorylated as described above, except that the phosphorylation reaction was terminated by the addition of $20 \mathrm{~mm}$ EDTA \pm exogenously added phosphatases. Homogenates were incubated with a mixture of purified phosphatases 1 and $2 \mathrm{~A}$ (PPC) or control buffer for $20 \mathrm{~min}$ at $30^{\circ} \mathrm{C}$ in buffer containing $10 \mathrm{mM}$ PIPES (pH 7.4), $10 \mathrm{mM} \mathrm{MgCl}_{2}$, and 

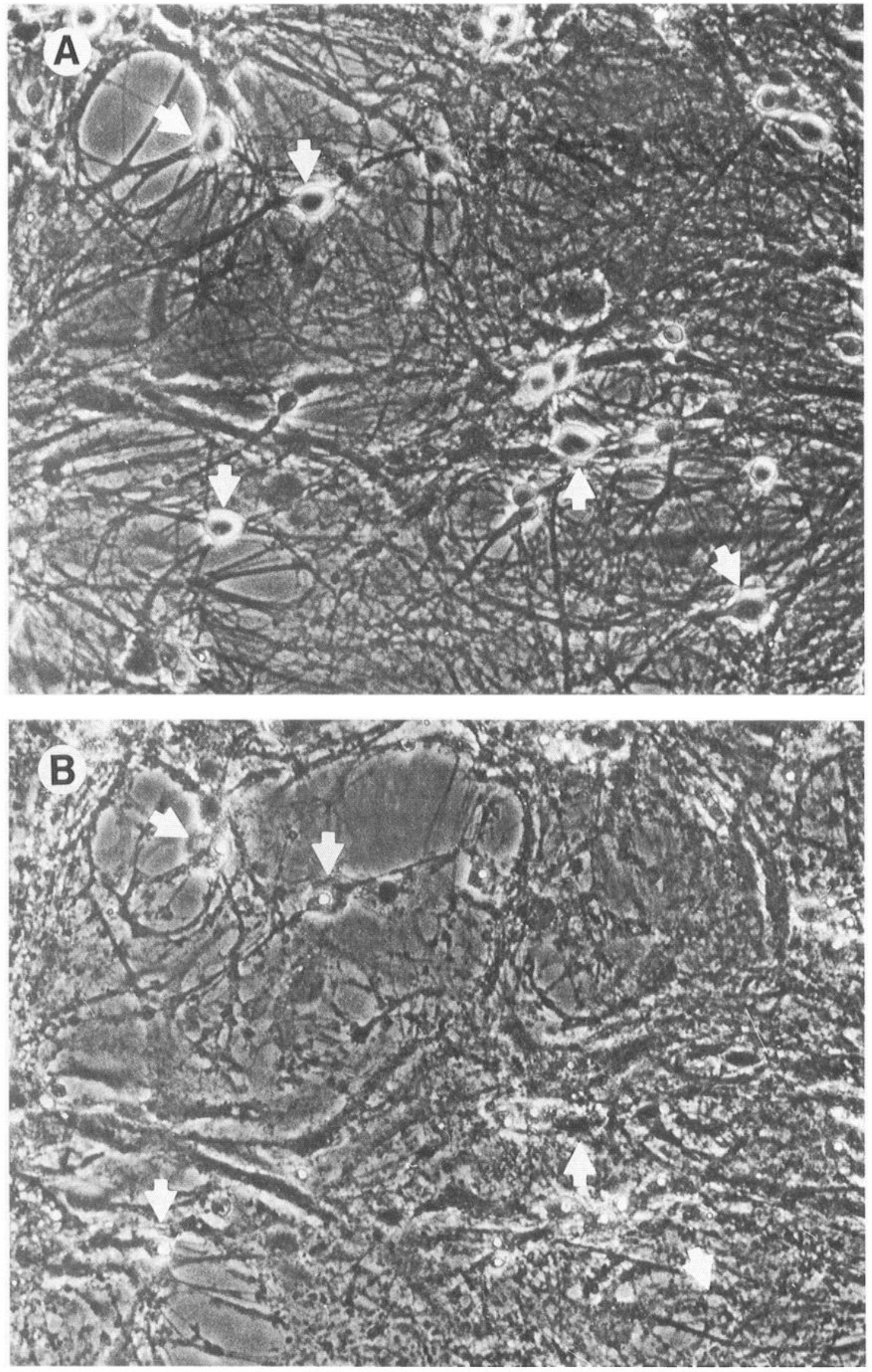

Figure 1. Photomicrographs showing nonaggregating hippocampal neuronal cultures before and following toxic glutamate exposure. A, Control hippocampal neurons exposed to culture medium for $10 \mathrm{~min}$ and observed $24 \mathrm{hr}$ after exposure. The neurons appear phase-bright with intact neuritic 
$0.5 \mathrm{~mm}$ DL-dithiothreitol (DTT) (Churn et al., 1990a,b, 1992a). Dephosphorylation reactions were continued for $20 \mathrm{~min}$ and terminated by protein solubilization with an SDS solution. In some experiments, the reaction was terminated by the addition of EDTA/PPC mixture +0.6 $\mu M$ okadaic acid (OA), a selective PPC inhibitor. Phosphatase activity was expressed as percent phosphate removed from maximally phosphorylated $\alpha$ subunit (Churn et al., 1992a).

To determine whether glutamate-induced inhibition was reversible with phosphatase treatment, homogenates from control and glutamatetreated cultures were pretreated with PPC as described above under conditions that were demonstrated to remove the majority of phosphate groups due to autophosphorylation. In reactions where subsequent kinase activity was tested, the incubation mixture also contained $600 \mu \mathrm{M}$ calmodulin. Phosphatase reactions were terminated by incubating samples with $0.6 \mu \mathrm{M}$ okadaic acid (BioMol, Plymouth Meeting) for $1 \mathrm{~min}$ at $30^{\circ} \mathrm{C}$. Following PPC treatment, standard $\mathrm{CaM}$ kinase II reactions were performed in the presence of $0.6 \mu \mathrm{M}$ okadaic acid to inhibit phosphatase activity as described previously (Churn et al., 1992a). Reactions were terminated, proteins resolved by SDS-PAGE and incorporation of phosphate quantitated as described above.

\section{Western analysis}

Proteins were resolved on SDS-PAGE under standard conditions and blotted onto nitrocellulose. Nitrocellulose was immersed in TWEENphosphate-buffered saline solution (TPBS); $10 \mathrm{mM} \mathrm{NaPO}_{4}, 0.9 \% \mathrm{NaCl}$, $\mathrm{pH} 7.5$ ) and $0.5 \% \mathrm{v} / \mathrm{v}$ TWEEN-20 (Sigma, St. I ouis). The nitrocellulose strip was incubated in TPBS containing a previously characterized anti- $\beta$ CaM kinase II antibody (IgG-3, monoclonal; Churn et al., 1992a,b) or anti- $\alpha$ antibody (Boehringer Mannheim, Indianapolis) for $1 \mathrm{hr}$. Unbound antibody was removed by three washings in TPBS. The blot was incubated in a solution of biotinylated secondary antibody in TPBS. Excess secondary antibody was removed by three washings with PBS (no TWEEN-20). Labeled proteins were reacted with an alkaline phosphatase staining kit (Vector, Burlingame). Development of bands was stopped by two changes of water. Developed strips were allowed to air dry and quantitation was performed by computer-assisted densitometry (Mocha, Jandel Corp., San Rafael, CA). Equal blotting of protein was confirmed by protein staining utilizing a sensitive gold staining procedure (Churn et al., 1992a,b) of parallel strips of nitrocellulose (Bio-Rad, Hercules). Strips of nitrocellulose were incubated in phosphate-huffered saline as above supplemented with 0.3\% TWEEN-20. Washed membranes were briefly rinsed in water and stained with AuroDye (BioRad, Richmond) until band formation reached saturation.

\section{Immunocytochemistry}

Hippocampal cells were plated onto a confluent glial feeder bed on 12 $\mathrm{mm}$ circular coverslips (Baxter, Columbia, MD) at a density $1 \times 10^{4}$ cells $/ \mathrm{mm}$. The lower cell density was utilized to facilitate photography of single neurons within the population. Slides were subjected to experimental conditions as described above and immediately fixed for 30 min with 5\% paraformaldehyde diluted into $0.1 \%$ PBS. Fixed cells were washed, and permeablized for $1 \mathrm{hr}$ with $0.1 \%$ saponin, $0.25 \%$ gelatin in PBS. Permeablized cells were exposed to 1C3-3D6 (1:200 dilution into PBS/SAP/GEL) for $1 \mathrm{hr}$. Treated cells were exposed to biotinylatedsecondary antibody (anti-mouse IgG, Vector) for 1 hour in PBS/SAP/ GEL. Cells were then treated with Texas red avidin (1:100 dilution in $\mathrm{PBS} / \mathrm{SAP} / \mathrm{GEL}$, Vector) for $30 \mathrm{~min}$. Cover slips were mounted onto slides with DABCO mounting media and allowed to dry for $30 \mathrm{~min}$. Slides were stored at $4^{\circ} \mathrm{C}$ in the dark until analyzed. Photomicroscopy was performed using a Nikon inverted microscope with original magnification of $40 x$.

\section{Measurement of intracellular calcium}

The ACAS confocal interactive laser cytometer was utilized to study intracellular calcium $\left(\left[\mathrm{Ca}^{2+}\right]_{i}\right)$ in hippocampal neurons under identical conditions utilized to investigate CaM kinase II activity and neuronal cell death. Neurons were preloaded with a fluorescent calcium binding probe (Indo-1) and changes in cellular fluorescence levels were monitored through whole cell imaging using ACAS confocal imaging (see below). Estimation of the change in free $\left[\mathrm{Ca}^{2+}\right]_{i}$ was determined by quantitating the ratio of Indo-1 fluorescence changes of free Indo-1 versus calcium-bound Indo-1 (see below). Culture medium was replaced with several washings of recording solution as described for biochemical and survival studies. For experimental conditions, simultaneous removal and addition of recording medium + either $500 \mu \mathrm{M}$ glutamate or $50 \mathrm{~mm} \mathrm{KCl}$ was performed. In some experiments, extracellular calcium was omitted or the selective NMDA antagonist, MK-801 (20 $\mu \mathrm{M})$, was included as described in the figure captions. The specific $\left[\mathrm{Ca}^{2+}\right]_{i}$ imaging methodology is described below:

Cell loading with Indo-1. To load hippocampal neurons with Indo-1, neuronal feed was removed and replaced with Recording solution (145 $\mathrm{mM} \mathrm{NaCl}, 2.5 \mathrm{~mm} \mathrm{KCl}, 10 \mathrm{~mm}$ HEPES, $10 \mathrm{~mm}$ glucose, $2 \mathrm{~mm} \mathrm{CaCl}$, $1 \mathrm{mM} \mathrm{MgCl}$, pH 7.3, osmolarity adjusted to 325 with sucrose) containing $1 \mu \mathrm{M}$ Indo- $1 \mathrm{AM}$. Loading of cells was performed at $37^{\circ} \mathrm{C}$ for 45 minutes. Cells were then washed three times with recording solution and incubated for an additional $15 \mathrm{~min}$ to allow for the cleavage of the Indo-1 AM to the free acid form by cellular esterases.

Microfluorometry. After neuronal cells were loaded with Indo-1, $\left[\mathrm{Ca}^{2+}\right]_{i}$ was measured using the ratio program (image analysis mode) of a confocal ACAS 570 Interactive Laser Cytometer (Meridian Instruments, Okemos, MI). Coverglass chambers were secured on the ACAS moving stage and analyzed using a $100 \times$ inverted oil immersion objective lens (Olympus, Lake Success, NY). Step size was adjusted such that multiple cells could be monitored simultaneously and analyzed individually. Calcium transients were expressed as the average of multiple cells. Confocal microscopy was utilized to ensure that calcium measurements were of hippocampal neurons. Using the manufacturer's optics set for Indo-1, $100 \mathrm{~mW}$ of a $360 \mu \mathrm{m}$ line of argon laser was used to excite the Indo-1. Photomultiplier strength was held constant in all experiments, and a $1 \%$ neutral density filter was used to prevent Indo-1 photobleaching. The ratio of emitted wavelengths at $405 \mu \mathrm{m}$ (Indo-1calcium complex) and $485 \mu \mathrm{m}$ (free Indo-1) was monitored to indicate relative calcium concentration. Free $\left[\mathrm{Ca}^{2+}\right]_{i}$ was estimated by comparison of fluorescence ratio values to a calcium calibration curve. All experiments were performed in recording solution at room temperature.

Calcium calibration curve. In order to convert fluorescent ratios to calcium concentration, an aqueous, in vitro calcium calibration curve was performed according to the method recommended by Meridian Instruments. Experimental parameters were consistent with those from cell culture experiments, and the buffer used was designed to approximate intracellular conditions $(100 \mathrm{~mm} \mathrm{KCl}, 1 \mathrm{~mm}$ EGTA, $50 \mathrm{~mm}$ HEPES, pH 7.2). The curve was generated by measuring the change in fluorescence after adding known amounts of calcium to buffer containing $10 \mu \mathrm{M}$ Indo-1 pentapotassium salt (nonpermeant). $K_{d}$ values of EGTA and Indo-1 were stabilized by the high concentration of HEPES in the buffer and by reducing temperature to $21^{\circ} \mathrm{C}$. EGTA correction of the calcium calibration curve was performed using ACAS software (Meridian Instruments, Okemos, MI) assuming $K_{d}$ values of $0.151 \mu \mathrm{M}$ for EGTA and $0.250 \mu \mathrm{M}$ for Indo- 1

\section{Results}

Characterization of the cell culture population. Hippocampal cells were plated onto a confluent glial bed at a density of 7.5 $\times 10^{5}$ cells/60 mm dish (Fig. 1). In mature cultures, viable neurons could be distinguished from glial cells as large, phase-bright cells with long branching neuritic processes (Fig. 1A). In contrast, glial cells appeared flat and polygonal in morphology and did not develop an extensive network of axons or dendrites. Approximately $30 \%$ of the neurons in the cultures were identified morphologically as pyramidal ncurons (Coulter et al., 1992). Exposure of cultures to $500 \mu \mathrm{M}$ glutamate for $10 \mathrm{~min}$ resulted in a reproducible, delayed neuronal cell death. Nonviable neurons exhibited fragmented processes (Fig. 1B) and did not exclude the vital dye, trypan blue (data not shown). Cell morphology was observed $24 \mathrm{hr}$ following the exposure of cultures to control, glutamate or glutamate plus MK-801 solutions. Ex- 


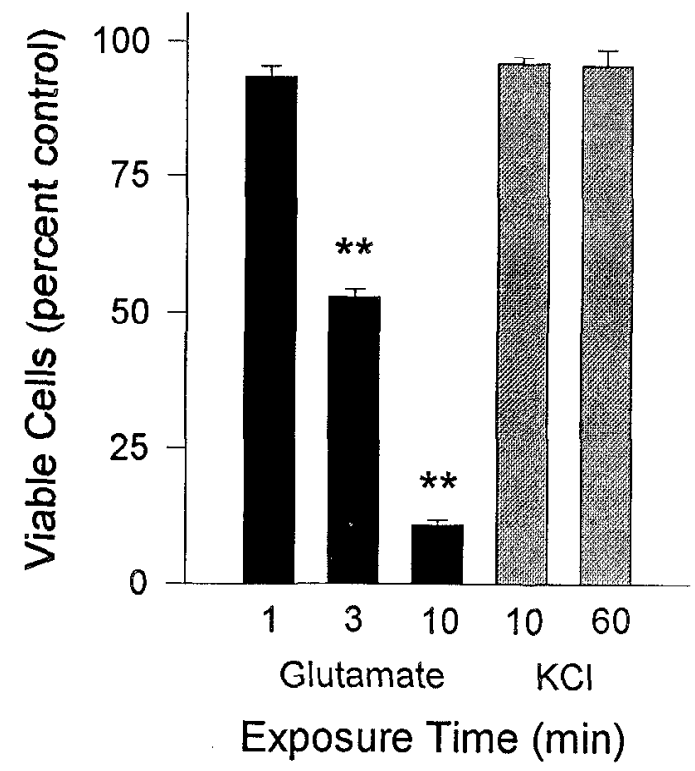

Figure 2. Effect of glutamate and KCl-depolarization on neuronal viability $24 \mathrm{hr}$ postexposure. Neurons were exposed to glutamate $(500$ $\mu \mathrm{M}$, solid bars, $n=8)$ or $\mathrm{KCl}(50 \mathrm{mM}$, hatched bars, $n=3)$ for the time indicated and allowed to recover for $24 \mathrm{hr}$ as described in the Materials and Methods. Viable neurons expressed as the mean percent \pm SEM of original neurons/dish. **, $p<0.001$ 1-way ANOVA, Bonferroni corrected.

citotoxic glutamate exposure $(500 \mu \mathrm{M}$, for $10 \mathrm{~min})$ resulted in $89.33 \pm 0.73 \%$ loss of hippocampal neurons after $24 \mathrm{hr}$ (Fig. 2), confirming results reported previously (Choi et al., 1987; Churn et al., 1993). Approximately $29.61 \pm 2.13 \%$ neuronal loss was observed after $1 \mathrm{hr}$ of glutamate exposure. The acute toxic reaction to glutamate exposure confirms previously reported acute neuronal loss and is probably sodium or chloride dependent (Choi, 1987). Control cultures did not exhibit a significant loss of viable neurons $(2.68 \pm 1.2 \%$ loss, $n=6)$. Therefore, any cell loss during the first $24 \mathrm{hr}$ following glutamate exposure was due predominately to glutamate treatment and not due to an artifact of handling the cultures.

The excitotoxic effect of glutamate on neuronal viability was dependent upon both duration of glutamate exposure and glutamate concentration (Fig. 2). Decreasing the time of neuronal exposure to glutamate resulted in decreased cell loss relative to $10 \mathrm{~min}$ exposure after $24 \mathrm{hr}$ (Fig. 2). Glutamate exposure for 1 min did not result in significant loss of viable neurons $(6.55 \pm$ $3.23 \%$ loss, $n=8$ ). Glutamate exposure for $3 \mathrm{~min}$ resulted in a $47.31 \pm 2.9 \%$ loss compared to control treatment. The percent cell death for the 3 min exposure was significantly different from both control and $10 \mathrm{~min}$ exposure times $(p<0.001$, one-way ANOVA, Bonferroni corrected). Reducing glutamate concentration to $50 \mu \mathrm{M}$ modulated the level of neuronal cell death. Exposure of neurons to $50 \mu \mathrm{M}$ glutamate for $3 \mathrm{~min}$ did not result in significant neuronal cell death $(14.09 \pm 1.4 \%$ loss, $n=8)$. However, $10 \mathrm{~min}$ of exposure to $50 \mu \mathrm{M}$ glutamate resulted in a significant loss of viable neurons $(79.4 \pm 2 \%$ loss, $n=9)$. Thus, the glutamate-induced, delayed neuronal cell death was dependent on both glutamate concentration and exposure duration.

To determine whether depolarization and entry of calcium through voltage-dependent channels could account for the glutamate-induced neuronal cell death, cultures were treated with $50 \mathrm{mM} \mathrm{KCl}$ under analogous conditions to glutamate exposure
(Fig. 2). Depolarizing cultured neurons with $50 \mathrm{~mm} \mathrm{KCl}$ for 10 min did not result in significant loss of viable neurons $(4.2 \pm$ $1.8 \%$ loss, $n=3$ ). In addition, extending the $\mathrm{KCl}$ exposure to $60 \mathrm{~min}$ did not result in significant loss of viable ncurons $(4.5$ $\pm 3 \%$ loss, $n=3$ ). Previous studies from this laboratory have demonstrated that $50 \mathrm{~mm} \mathrm{KCl}$ treatment of the cultured produced complete neuronal depolarization (Coulter et al., 1992). These observations suggest that calcium entering through voltage-gated calcium channels was not sufficient, alone, to cause the delayed neuronal cell death. These observations also provided a mechanism for inducing prolonged increases in intracellular calcium which did not result in delayed neuronal cell death. The findings are consistent with the results from other studies (Choi, 1988; Choi and Hartley, 1993; Churn et al., 1993) confirming that the effects of calcium on cell death depend upon the mechanism of calcium entry.

Effects of glutamate and depolarization on neuronal calcium levels. It is important to document the levels of intracellular free calcium $\left(\left[\mathrm{Ca}^{2+}\right]_{i}\right)$, under conditions utilized to quantitate neuronal cell death and CaM kinase II inhibition. ACAS confocal analysis of Indo- 1 fluorescence was utilized to directly measure transient increases in $\left[\mathrm{Ca}^{2+}\right]_{i}$ following pharmacologic stimulation with either $500 \mu \mathrm{M}$ glutamate or $50 \mathrm{mM} \mathrm{KCl}$ solutions (Fig. 3). Healthy neurons displayed basal $\left[\mathrm{Ca}^{2+}\right]_{i}$ levels between $100-150$ $\mu \mathrm{M}$. Cultures with neurons displaying basal $\left[\mathrm{Ca}^{2 \cdot}\right]_{i}$ levels greater than $150 \mu \mathrm{M}$ were not used for experimentation (Murphy and Miller, 1988). Excitotoxic (10 min) glutamate exposure resulted in an initial increase in $\left[\mathrm{Ca}^{2+}\right]_{i}$ to greater than $2 \mu \mathrm{M}(n=20$ neurons) followed hy a sustained $\left[\mathrm{Ca}^{2+}\right]_{i}$ transient. In addition, the $\left[\mathrm{Ca}^{2+}\right]_{i}$ transient persisted after the glutamate solution was replaced with control solution. Coadministration of MK-801 with the glutamate (Fig. $3 C$ ) significantly reduced the initial $\left[\mathrm{Ca}^{2+}\right]_{i}$ transient and all cells returned to normal $\left[\mathrm{Ca}^{2+}\right]_{i}$ levels upon removal of glutamate ( $n=8$ neurons). To determine whether the increase in $\left[\mathrm{Ca}^{21}\right]$, was due predominantly to influx of extracellular $\mathrm{Ca}^{2+}$, glutamate exposure was performed in the absence of extracellular $\mathrm{Ca}^{2+}$. Cultures were washed four times with $\mathrm{Ca}^{2+}$-free recording solution and subjected to excitotoxic glutamate in the absence of $\mathrm{Ca}^{2+}$. Removal of extracellular calcium blocked both the initial rise in $\left[\mathrm{Ca}^{2+}\right]_{i}$ as well as the sustained $\left[\mathrm{Ca}^{2+}\right]_{i}$ transient (Fig. $3 D ; n=7$ neurons). Thus, both the initial rise in $\left[\mathrm{Ca}^{2+}\right]_{i}$ and the glutamate-induced, sustained calcium transients were shown in our cultures and as described by others (Abele et al., 1990; Connor and Tseng, 1988) to be dependent upon extracellular $\mathrm{Ca}^{2+}$ and stimulation of the NMDA subtype of glutamate-gated channels. Exposure of neurons to 50 $\mathrm{mm} \mathrm{KCl}$ for $10 \mathrm{~min}$ (Fig. $3 B$ ) resulted in an initial increase in $\left[\mathrm{Ca}^{2+}\right]_{i}$, to approximately $2.4 \mu \mathrm{M}$ with a smaller $\left[\mathrm{Ca}^{21}\right]_{i}$ transient that rapidly returned to baseline levels following removal of $\mathrm{KCl}$ solution (n -9 neurons). Thus, stimulation of neurons with 50 $\mathrm{mM} \mathrm{KCl}$ resulted in an initial peak of $\left[\mathrm{Ca}^{2+}\right]_{\text {, which was similar }}$ to glutamate exposure, but did not produce a sustained, elevated $\left[\mathrm{Ca}^{2+}\right]_{i}$ transient as was observed with $500 \mu \mathrm{M}$ glutamate.

Effects of glutamate exposure on CaM kinase II activity. Homogenates from control hippocampal neuronal cultures were reacted under standard conditions (see Materials and Methods) which were maximal for CaM kinase II activity and resolved by SDS-PAGE (Fig. 4). Homogenates from control cultures demonstrated calcium stimulated phosphate incorporation into specific protein bands in comparison to magnesium-dependent (basal) phosphorylation. The calcium-dependent phosphorylation pattern observed in hippocampal cultures was similar to that 


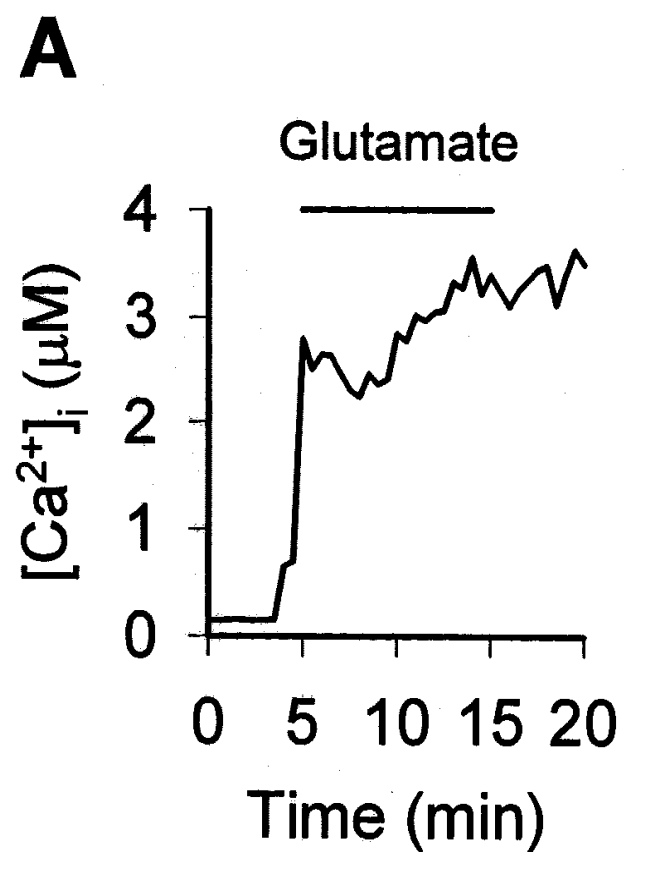

B
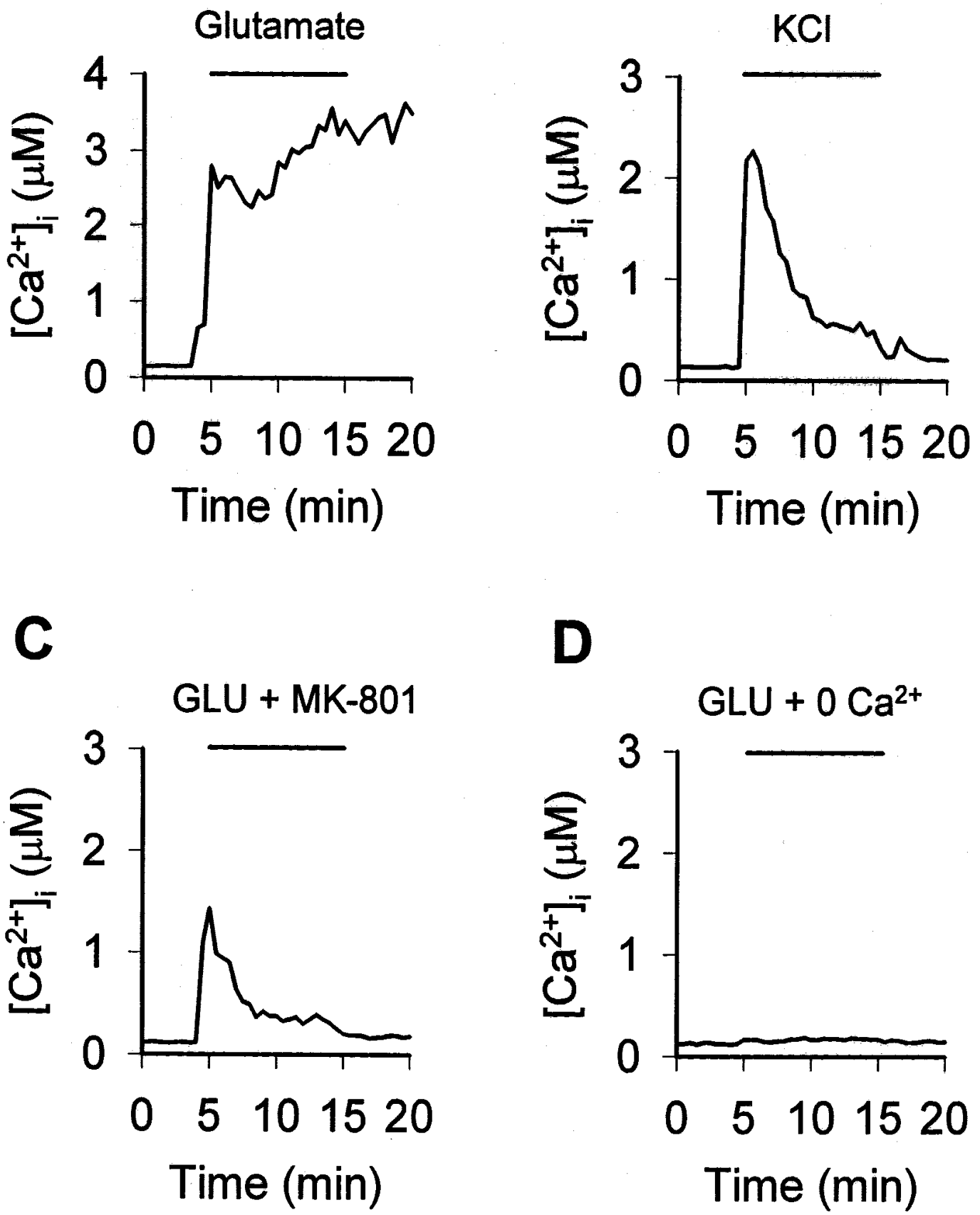

D

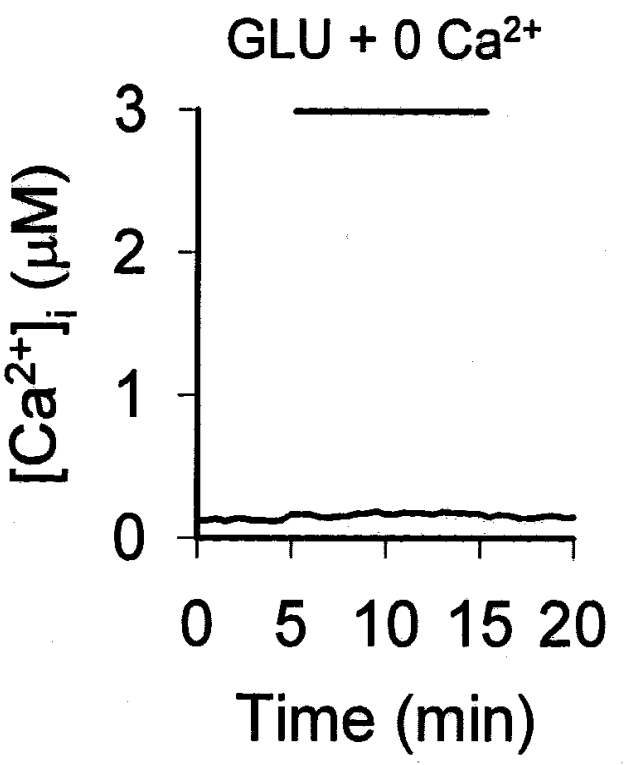

Figure 3. Effect of glutamate and $\mathrm{KCl}$-depolarization on $\left[\mathrm{Ca}^{2+}\right]_{i}$ in hippocampal neurons in culture. Neurons cultured for $12 \mathrm{~d}$ were used for all experiments. Neurons were preloaded with Indo-1 under standard conditions (see Materials and Methods) and transferred to the confocal fluorescence microscope. Solutions were rapidly added and removed with a flow through system that did not affect the cells. Cultured neurons were constantly in view during all experimental manipulations. The neurons were exposed for $10 \min$ to, in $A, 500 \mu \mathrm{M}$ glutamate, $n=20 ; B, 50 \mathrm{mM} \mathrm{KCl,} n=9$; $C, 500 \mu \mathrm{M}$ glutamate $+\mathrm{MK}-801, n=8$; and $D, 500 \mu \mathrm{M}$ glutamate in the presence of $0\left[\mathrm{Ca}^{2+}\right]_{o}, n=7$ neurons. After removal of the treatment conditions, neurons were maintained in recording solution for continued observation. The bar in each figure denotes the time of treatment application. ACAS confocal imaging of Indo- 1 fluorescence (see Materials and Methods) was utilized to estimate free $\left[\mathrm{Ca}^{2+}\right]_{i} . \mathrm{Molar}\left[\mathrm{Ca}^{2+}\right]_{i}$ levels were determined by comparing fluorescence intensity with a calibration curve (Meridian Instruments, Okemos). Figures show the average $\left[\mathrm{Ca}{ }^{2+}\right]_{i}$ values obtained from multiple recordings ( $n$ values given above).

observed in preparations from whole brain, hippocampal slices, and from mixed cortical neuronal cultures (Churn et al., 1990a, 1992a, 1993). Although CaM kinase II activity has been reported in glial cells (Babcock-Atkinson et al., 1989), no significant CaM kinase II activity was observed in glial cells cultured in the absence of neurons when incubated under standard conditions utilized to measure kinase activity in neuronal cultures (data not shown). Thus, CaM kinase II activity observed in neuronal culture was primarily expressed in neuronal cells and was not from glial cell contamination. Comigration with purified 


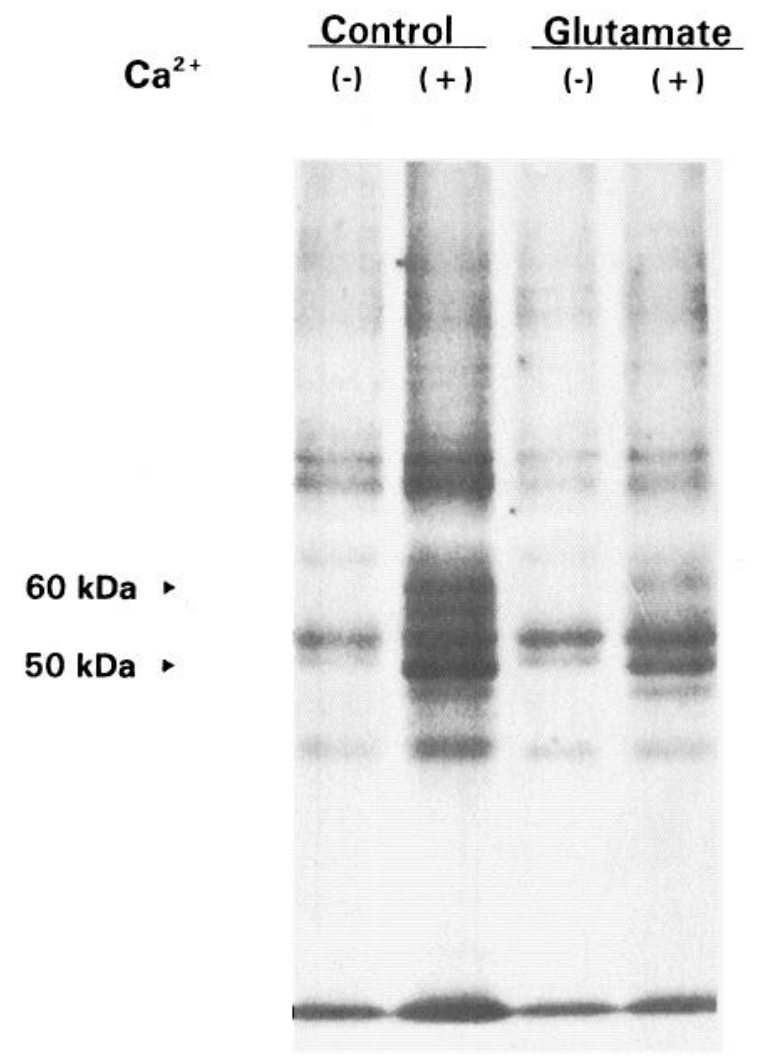

Figure 4. Effect of glutamate on endogenous CaM kinase II activity in hippocampal neurons. The autoradiograph from a representative sodium dodecyl sulfate-polyacrylamide gel electrophoresis of hippocampal culture homogenates reacted under standard conditions for CaM kinase II activity (see Materials and Methods). Endogenous phosphorylation was measured in the absence $(-)$ and presence $(+)$ of calcium and calmodulin as described in Materials and Methods. Arrows denote the $\alpha(50 \mathrm{kDA})$ and $\beta(60 \mathrm{kDA})$ subunits of CaM kinase II. CaM kinase II activity was routinely measured by quantitation of $\alpha$ subunit autophosphorylation (see Materials and Methods).

CaM kinase II on high resolution gel electrophoresis has been utilized to identify the $50 \mathrm{kDa}(\alpha)$ and $60 \mathrm{kDa}(\beta)$ subunits of CaM kinase II in forebrain homogenates and neuronal cultures (Churn et al., 1990a, 1993). Comigration with purified rat CaM kinase II was utilized to identify the $50 \mathrm{kDa}$ and $60 \mathrm{kDa}$ subunits as the alpha and beta subunits of CaM kinase II in hippocampal cell culture (Fig. 4, arrows). The peptide bands in the cellular homogenate comigrating with purified CaM kinase II were further demonstrated to be the $\alpha$ and $\beta$ subunits of the kinase by immunoreactivity with specific antibodies directed against these subunits by Western analysis (see Materials and Methods).

Excitotoxic glutamate exposure that produced significant neuronal death after $24 \mathrm{hr}$ (Fig. 2) and elevated $\left[\mathrm{Ca}^{2+}\right]_{i}$ (Fig. 3) in hippocampal cells resulted in a $41 \pm 1.9 \%$ inhibition of CaM kinase II activity when assayed $1 \mathrm{hr}$ after glutamate exposure (Fig. 5). The observed glutamate-induced inhibition was significant when compared to control cultures $(p<0.01$, one-way ANOVA, Bonferroni corrected). Short-term exposure (1-3 min) of hippocampal cells to glutamate did not result in significant inhibition of CaM kinase II activity (data not shown). In addition, exposure of cultures to $50 \mathrm{~mm} \mathrm{KCl}$ for $10 \mathrm{~min}$ did not result in inhibition of CaM kinase II activity ( $97 \%$ of control, $n$ $=12$ cultures; Fig. 5). Thus, glutamate exposures that resulted in significant delayed neurotoxicity and prolonged elevations in

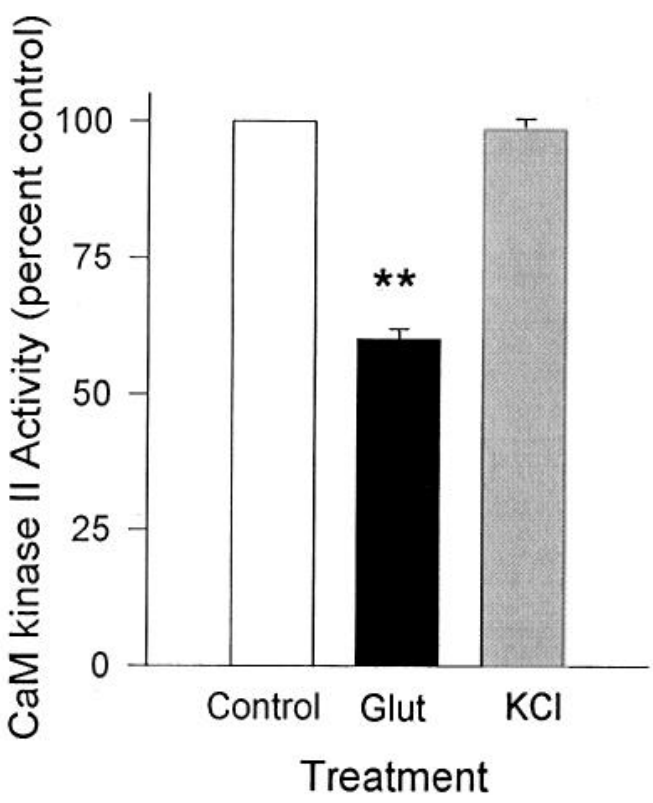

Figure 5. Effect of glutamate $(500 \mu \mathrm{M})$ or $\mathrm{KCl}(50 \mathrm{~mm})$ on $\mathrm{CaM}$ kinase II activity in hippocampal homogenates. Hippocampal neurons in culture were exposed to glutamate $(n=11)$ or $\mathrm{KCl}(n=12)$ for 10 min under standard conditions and allowed to recover for $\mathrm{I} \mathrm{hr}$ as described in Materials and Methods. The cultures were then harvested and endogenous kinase activity was quantitated as described in Materials and Methods. Endogenous kinase activity was calculated as percent of kinase activity in parallel sham-treated cultures. Data are presented as mean \pm SEM. $* *, p<0.001$, one-way ANOVA, Bonferroni corrected.

$\left[\mathrm{Ca}^{2+}\right]_{i}$ resulted in significant inhibition of CaM kinase II activity. Conversely, depolarizing conditions that did not result in significant neuronal death or prolonged elevations in $\left[\mathrm{Ca}^{2+}\right]_{i}$, also did not result in significant inhibition of CaM kinase II activity.

To determine the time course of excitotoxic glutamate receptor activated inhibition of CaM kinase II activity, hippocampal neurons were assayed for kinase activity after different time intervals following a standard $10 \mathrm{~min}$ glutamate exposure. After excitotoxic exposure, significant inhibition of CaM kinase II activity was observed at all time points measured (Fig. 6). CaM kinase II inhibition was observed immediately following excitotoxic exposure to glutamate $(46.1 \pm 6.9 \%$ inhibition, $n=6$ cultures) and remained diminished at all points measured. The data suggest that excitotoxicity-induced inhibition of CaM kinase II activity occurred, it remained until significant neuronal death was observed. Thus, glutamate-induced excitotoxicity was observed immediately following a $10 \mathrm{~min}$ glutamate exposure and at every time point measured, up to $1 \mathrm{hr}$. In addition, the observed inhibition of CaM kinase II activity preceded the glutamate-induced, calcium-dependent neuronal cell death.

To further determine whether the observed inhibition of kinase activity was due to autophosphorylation with cold phosphate groups, CaM kinase II-dependent phosphorylation of exogenously-added synthetic peptide (Syntide II) was performed (Fig. 7), utilizing established procedures (Hashimoto and Soderling, 1987). Under standardized conditions, Syntide II phosphorylation was inhibited in fractions obtained from glutamatetreated cultures $(68.1 \pm 1 \%$ of control, $n=4)$. In addition, the inhibition observed in the Syntide II phosphorylation assays was equivalent to the inhibition observed in the back phosphorylation assays $(68.8 \pm 2.3, n=4)$. Therefore, the glutamate-in- 


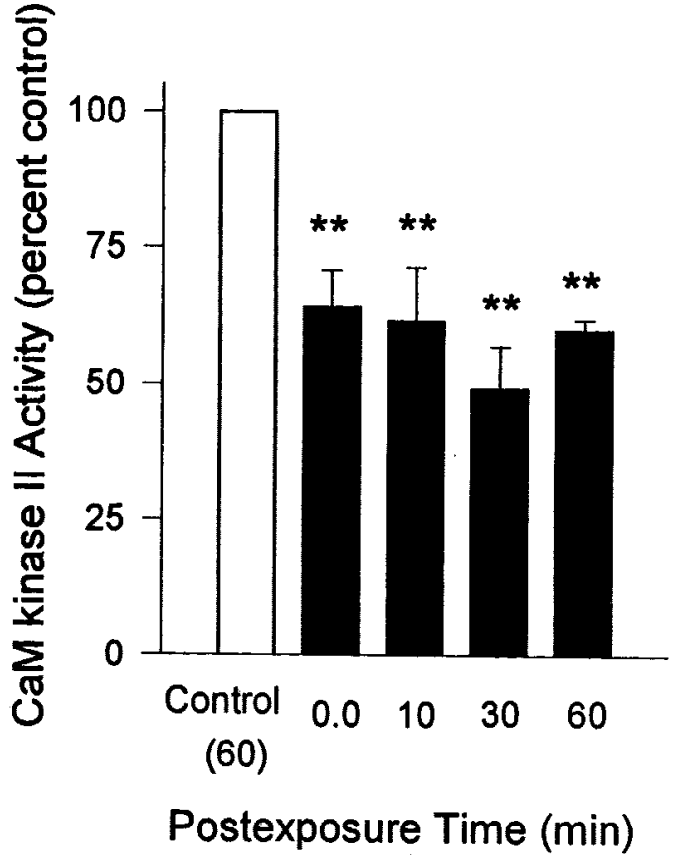

Figure 6. Time course of glutamate-induced inhibition of CaM kinase II activity. Cultures were exposed to control or glutamate solutions for $10 \mathrm{~min}$ and harvested at the time point indicated. The excitotoxic glutamate exposure which induced delayed neuronal cell death also induced an immediate inhibition of CaM kinase II activity which persisted for all time points measured. Data represent mean \pm SEM of control kinase activity ( $n=6$, each group).

duced inhibition of CaM kinase II activity observed in the back phosphorylation assays was due to inhibition of enzyme activity and not due to prelabeling with cold phosphate groups of the kinase subunits.

To further characterize Syntide II phosphorylation, saturation experiments were conducted. The glutamate induced inhibition of CaM kinase II activity could not be overcome by either increasing Syntide II concentration or time of reaction (Fig. 8). Syntide II phosphorylation displayed an apparent $k_{M}$ of $11.4 \mu \mathrm{M}$ in control homogenates and $10.2 \mu \mathrm{M}$ in glutamate treated cultures. However, maximal Syntide II phosphorylation in glutamate-treated cultures was decreased $36.9 \%$ when compared to control phosphorylation (Fig. 8). In addition, the glutamate-induced inhibition of Syntide II phosphorylation could not be overcome by increasing reaction time (Fig. 8). The $k_{1 / 2}$ was not significantly different in glutamate-treated cultures when compared to control (control $k_{1 / 2}=31.2 \mathrm{sec}$ vs glutamate-treated $k_{1 / 2}$ $=38 \mathrm{sec}$ ). However, the maximal Syntide II phosphorylation in glutamate-treated cultures did not approach control phosphorylation levels at any time point measured. Maximal Syntide II phosphorylation was $45.6 \%$ of control phosphorylation using saturating levels of substrate (Fig. 8). Thus, glutamate-induced inhibition of CaM kinase II activity was observed when utilizing autophosphorylation as well as exogenously added Syntide II as a substrate. In addition, the glutamate-induced inhibition of CaM kinase II activity could not be overcome by increasing either Syntide II concentration or time of reaction.

Glutamate-induced inhibition of CaM kinase II was not due to autophosphorylation. Autophosphorylation has been shown to modulate CaM kinasc II activity (Lai et al., 1986; Ilanson and Schulman, 1992). In addition, CaM kinase II exists in an

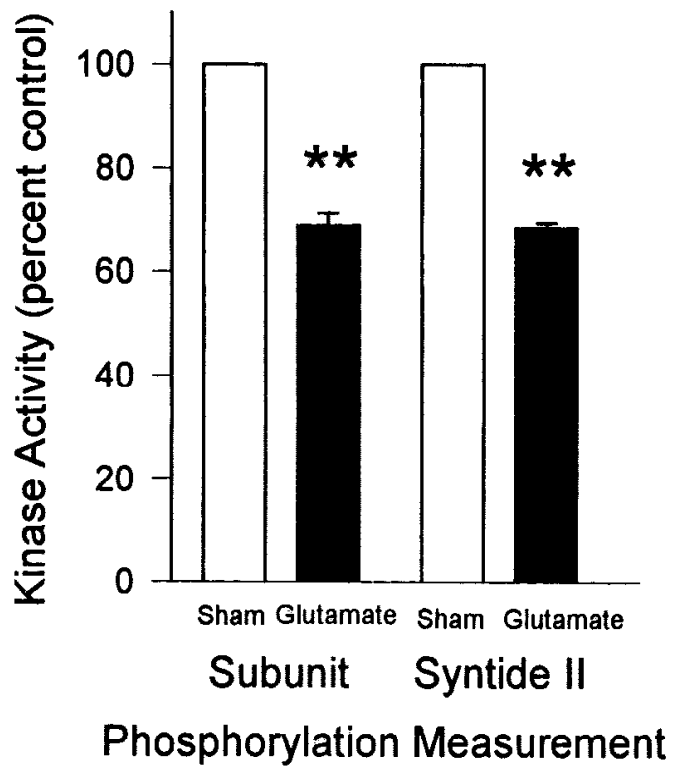

Figure 7. Glutamate-induced inhibition of CaM kinase II activity is equivalent when measured by autophosphorylation of the $\alpha$ subunit and phosphorylation of exogenously added substrate. Glutamate-induced inhibition of CaM kinase II activity was measured by standard autophosphorylation methods $(n=4)$ and P-81 assay of syntide II phosphorylation in the same samples (see Materials and Methods). Glutamate induced inhibition of kinase activity was equivalent when measured by either technique. The data represent the mean \pm SEM of control kinase activity. **, $p<0.001$, one-way ANOVA, Bonferroni corrected.

equilibrium of the phosphorylated and nonphosphorylated states which may complicate the interpretation of in vitro phosphorylation assays (Patton el al., 1993). Although the exogenous substrate studies performed above strongly rule out autophosphorylation as the cause of glutamate-induced inhibition of kinase autophosphorylation, it may still be possible that potential phosphorylation sites were already phosphorylated in glutamatetreated samples and thus not available for phosphorylation, in vitro. To determine whether de novo autophosphorylation of CaM kinase II had occurred, bomogenates from control and glutamate-treated cultures were treated with phosphatase 1 and $2 \mathrm{~A}$ (PPC) under conditions that were shown to effectively remove endogenous phosphates from CaM kinase II (Shields et al., 1985; Churn et al., 1992a).

To determine whether phosphatases 1 and $2 \mathrm{~A}$, could remove autophosphorylation-dependent phosphate groups, autophosphorylation reactions were performed and terminated by the addition of PPC mixture. Removal of radioactive phosphate groups was quantitated over time by removing aliquots and resolving the proteins by SDS-PAGE (Fig. 9). Partial dephosphorylation of endogenous kinase subunits was observed in buffer alone. The observed dephosphorylation was most likely due to endogenous phosphatases in the homogenate fractions. The dephosphorylation of CaM kinase II was more rapid and occurred to a significantly greater extent in the presence of exogenously added PPC (Fig. 9) removing greater than $70 \%$ of labeled phosphate groups added by autophosphorylation. Incubation of homogenates with both PPC and the selective phosphatase inhibitor okadaic acid $(600 \mu \mathrm{M})$ resulted in almost no removal of radioactive phosphate groups from the CaM kinasc II subunits. Thus, okadaic acid sensitive phosphatases were able to remove a signifi- 


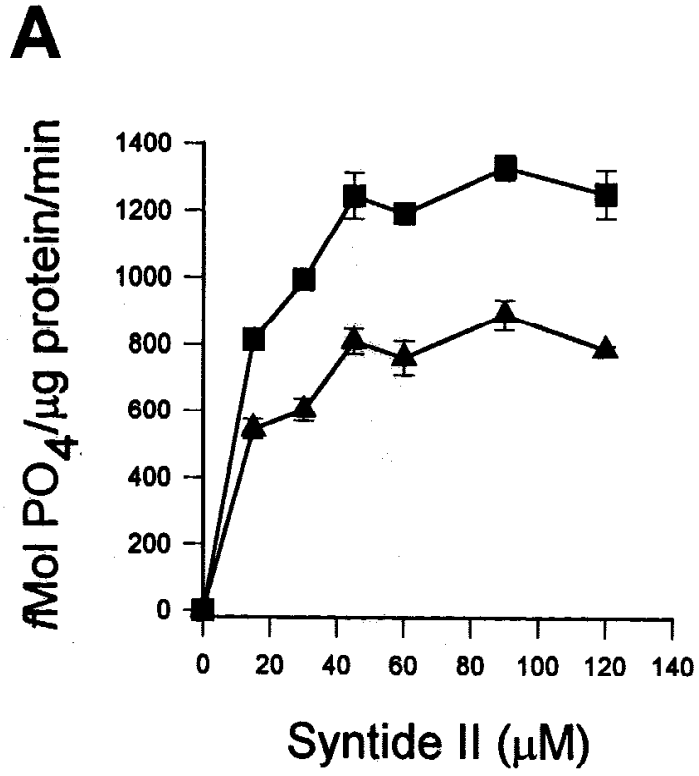

B

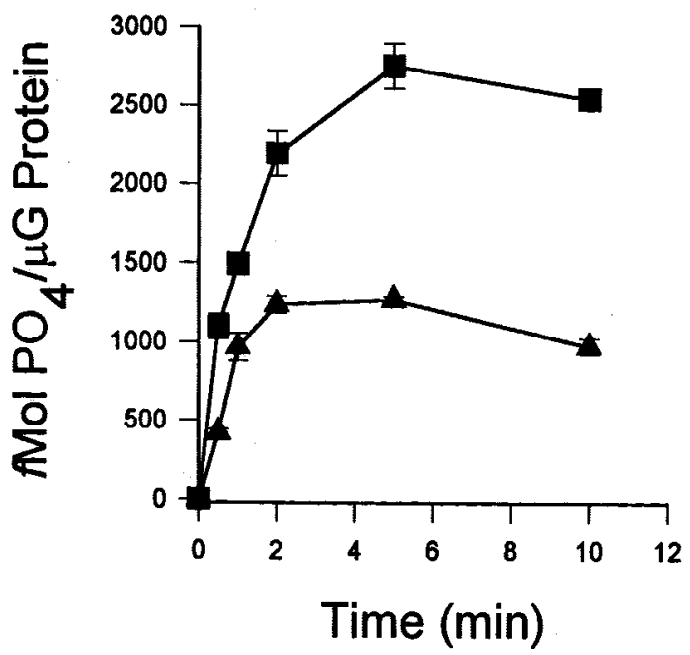

Figure 8. Syntide II phosphorylation in homogenates obtained from control (squares) and glutamate-treated (triangles) cultures. A, Syntide II saturation curves were generated in homogenates from control and glutamate-treated cultures. Significant inhibition of kinase activity was observed in glutamate-treated cultures $\left(V_{\max }=1437.4 \mathrm{fmol} / \mu \mathrm{g} / \mathrm{min}\right.$ control vs $909.1 \mathrm{fmol} / \mu \mathrm{g} / \mathrm{min}$, glutamate-treated) without alteration of $k_{M}$ (11.4 $\mu \mathrm{M}$ control vs $10.2 \mu \mathrm{M}$, glutamate-treated) when compared to control cultures. $B$, Syntide II phosphorylation time courses for homogenates obtained from control and glutamate-treated cultures. Increasing reaction time did not overcome glutamate-induced inhibition of $\mathrm{CaM}$ kinase II activity when measured by Syntide II phosphorylation. Glutamate treatment did not result in alteration of $k_{1 / 2}(31.2 \mathrm{sec}$, control vs $38 \mathrm{sec}$, glutamate treated). However, increasing reaction time did not overcome the glutamate-induced inhibition $\left(V_{\max } 2981 \mathrm{fmol} / \mu \mathrm{g}\right.$, control vs $1621 \mathrm{fmol} / \mu \mathrm{g}$, glutamate treated). Data shown are representative of multiple experiments. The data represent the mean \pm SEM of triplicate quantitations.

cant level of phosphate groups due to autophosphorylation of CaM kinase II.

Unlike autophosphorylation, the excitotoxicity-induced inhibition of CaM kinase II activity was not reversible with phos-

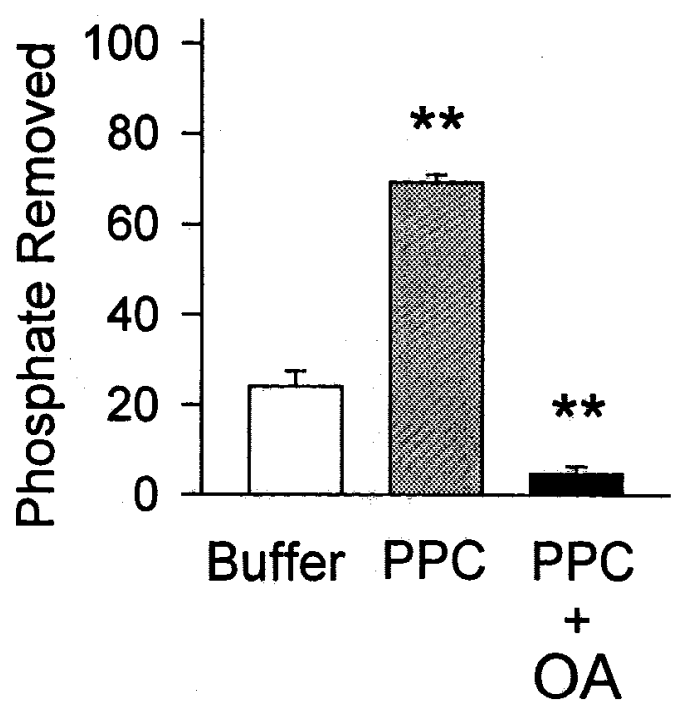

Figure 9. Activity of PPC in removing CaM kinase II phosphate groups due to autophosphorylation. Ilomogenates from control hippocampal cultures were phosphorylated as described in Materials and Methods. Autophosphorylation reactions were terminated by the addition of chelator buffer + PPC or PPC + OA. PPC reactions were continued for $20 \mathrm{~min}$ and terminated by solubilization of reactant proteins. Samples were resolved by SDS-PAGE and phosphate removal from the $\alpha(50 \mathrm{kDa})$ subunit quantitated by liquid scintillation counting (see Materials and Methods). Data are expressed as the mean percent \pm SEM phosphatase removed from CaM kinase II compared to zero time point ( $n=4$, each group). ${ }^{* *}, p<0.001$ different from control buffer solution, one-way ANOVA, Bonferroni corrected.

phatase treatment. Kinase from glutamate-treated cultures displayed $60.3 \%$ of control activity prior to phosphatase treatment and displayed $61.8 \%$ activity following treatment. Thus, the glutamatc-induced inhibition of CaM kinase II was not due to increased autophosphorylation of the enzyme in situ. Since no kinase activity could be recovered by the PPC treatment, it is unlikely that autophosphorylation, alone, could account for the glutamate-induced inhibition of CaM kinase II activity. Together with the substrate phosphorylation data, these results indicated that excitotoxic inhibition of CaM kinase II was not due to an aulophosphorylation-induced inhibition of the enzyme. However, the data does not exclude the possibility that phosphorylation at a site not recognized by the phosphatases used in the present study may account for some of the observed inhibition of kinase activity.

Pharmacology of glutamate-induced neurotoxicity. To determine which glutamate receptor subtype was responsible for the excitotoxicity-induced inhibition of CaM kinase II activity, specific glutamate receptor agonists and antagonists were employed (Fig. 10). Coincubation of neurons with glutamate + MK-801, a noncompetitive NMDA receptor antagonist, resulted in almost complete protection from the glutamate-mediated inhibition of CaM kinase II $(5.35 \pm 4.0 \%$ inhibition, $n=4)$. Alternatively, incubation with $100 \mu \mathrm{M}$ NMDA resulted in significant $(60 \pm$ $5.6 \%$ ) inhibition of CaM kinase II activity. Furthermore, coincubation of neurons with glutamate + CNQX $(100 \mu \mathrm{M})$, a potent AMPA receptor antagonist, did not result in significant protection from glutamate-induced inhibition of CaM kinase II activity $(52.7 \pm 4 \%$ inhibition, $n=4)$. Incubation with quisqualate, resulted in $33.72 \pm 10.17 \%$ inhibition of CaM kinase II activity $(n=4)$. However, the observed inhibition could be blocked with coincubation of quisqualate + MK-801 (9.17 $\pm 2.39 \%$ inhibi- 


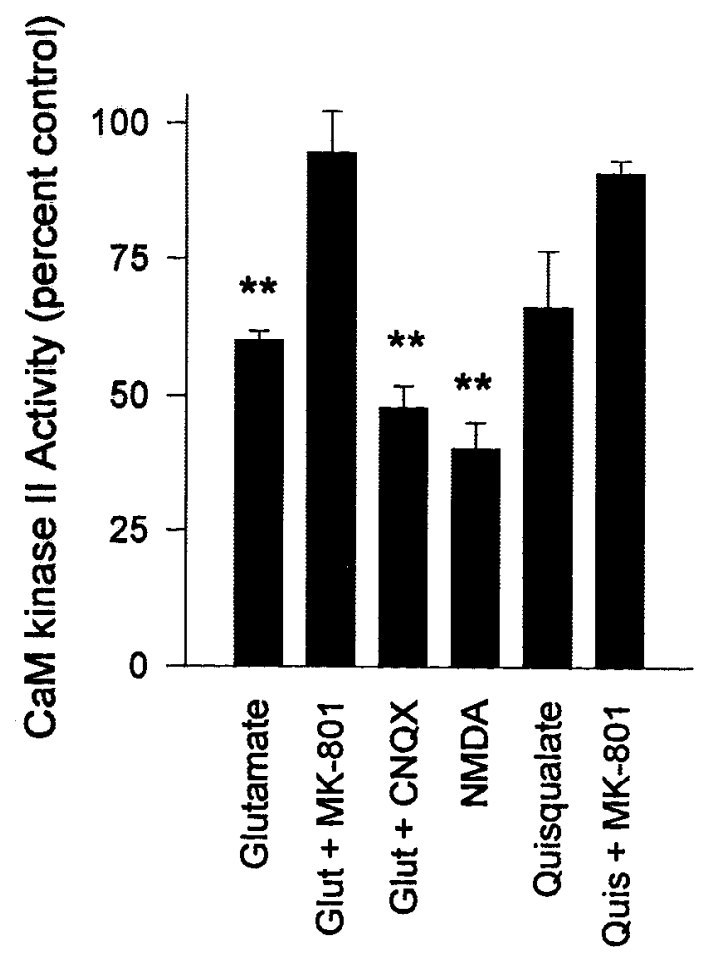

Figure 10. Pharmacology of glutamate-induced inhibition of CaM kinase II activity in hippocampal cultures. Hippocampal cultures were exposed to agents specified under standard excitotoxic conditions. Cultures were allowed to recover for $1 \mathrm{hr}$ and harvested for CaM kinase II quantitation. Endogenous kinase activity is expressed as the mean percent \pm SEM of sham-treated sister cultures; $n=4$, each group. **, $p<0.01$, one-way ANOVA, Bonferroni corrected

tion, $n=4$ ). Thus, the observed quisqualate induced inhibition of CaM kinase II activity probably was due to endogenous glutamate release and secondary stimulation of NMDA-dependent receptors. The data support the hypothesis that excitotoxic activation of the NMDA glutamate-receptor subtype can account for the excitutoxicity induced inhibition of CaM kinase II observed in this model.

Calcium dependence of excitotoxicity-induced inhibition of CaM kinase II activity. Previous reports have demonstrated the dependence of calcium on delayed neuronal toxicity (Choi et al., 1988; Michaels and Rothman, 1990) and the development of an extended neuronal depolarization (END, Coulter et al., 1992; Sombati et al., 1991). Therefore, we investigated whether a calcium-dependent mechanism was responsible for the NMDA-induced inhibition of CaM kinase II activity. To assess the effect of removal of calcium from the recording solution, cultures were washed with physiological saline without calcium. The cultures were then exposed to glutamate as described in the methods except that calcium was omitted in the glutamate-containing recording solution. In addition, calcium was omitted from the initial washing steps after glutamate exposure. Removal of calcium from the recording solution resulted in almost complete protection from glutamate-induced inhibition of CaM kinase II activity (Fig. 11). A calcium concentration curve was tested to determine the effect of various extracellular calcium on inhibition of $\mathrm{CaM}$ kinase II activity. Removal of extracellular $\mathrm{Ca}^{2+}$ during the glutamate exposure, prevented the glutamate-induced loss of CaM kinase II activity $(0.2 \pm 1.1 \%$ inhibition, $n=6)$. However, extracellular $\mathrm{Ca}^{2+}$ concentrations of $0.3,1$, and $2 \mathrm{mM} \mathrm{CaCl}_{2}$ in

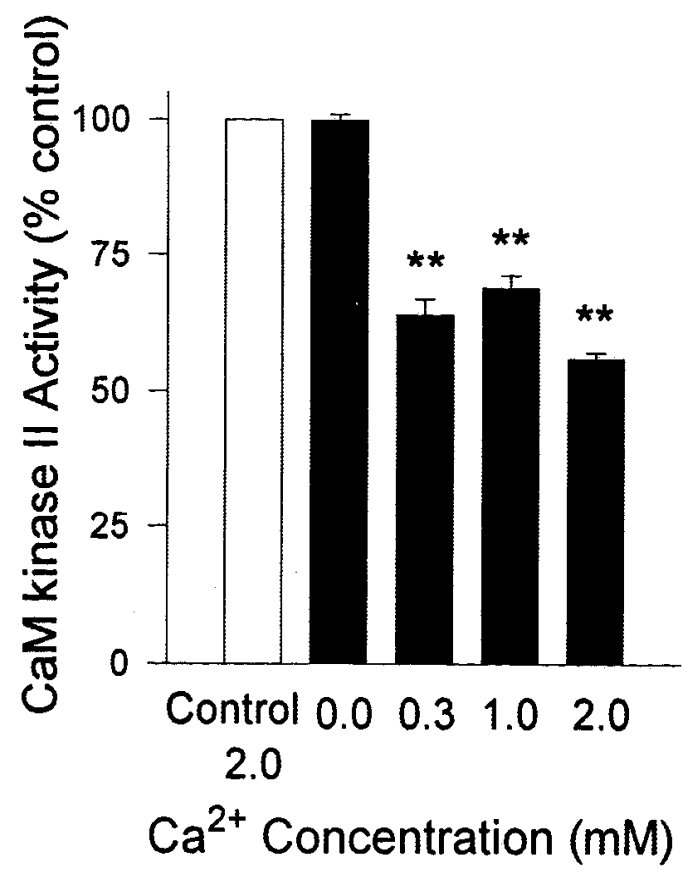

Figure 11. Effect of calcium on glutamate-induced inhibition of CaM kinase II activity. Hippocampal neurons were exposed to standard excitotoxic glutamate $(500 \mu \mathrm{M}, 10 \mathrm{~min})$ in the presence of varying extracellular calcium concentrations. Removal of calcium resulted in protection from glutamate-induced inhibition. Data are expressed as mean \pm SEM $(n=6) . p<0.001$, one-way ANOVA, Bonferroni corrected.

the presence of glutamate, resulted in similar levels of CaM kinase II inhibition $(36.1 \pm 2.9 ; 31.2 \pm 2.3 ; 44.2 \pm 1.2 \%$ inhibition, respectively). The results were similar to previously published observations of cation dependence on END (Coulter et al., 1992). Thus, the cation dependence for inhibition of CaM kinase Il activity parallels that observed for neurotoxicity (Choi et al., 1988; Michaels, Rothman, 1990) and the induction of END (Sombati et al., 1991; Coulter et al., 1992) in primary neuronal cultures.

Immunocytochemistry of CaM kinase II in neuronal culture. Our laboratory has developed a monoclonal $\operatorname{IgG}_{3}$ antibody against the beta subunit of CaM kinase II which does not recognize the ischemically modified enzyme in situ (Churn et al., $1992 a, b)$. This antibody was utilized to further characterize the inhibition of CaM kinase II activity in hippocampal cultures. Immunocytochemical analysis was performed on neurons exposed for $10 \mathrm{~min}$ to either control or glutamate solution (Fig. 12). Control cultures exhibited significant immunofluorescence which was specific to neuronal cells. The specific immunofluorescence demonstrated the high level of neuronal CaM kinase II expression relative to glial cells in culture. In glutamate-treated cultures, many neurons did not show significant immunofluorescence above background levels. In the remaining neurons that did show immunofluorescence, the level was significantly lower than control neurons (Fig. 12). In addition, the pattern of immunofluorescence was grainy and not homogenous compared to control cultured cells. Pyramidal neurons identified by morphology demonstrated a more significant decrease in CaM kinase II immunoreactivity than other neuronal cell types. Thus, excitotoxic glutamate exposure resulted in a loss of immunofluorescence that was observed immediately following excitotoxic exposure of neuronal cultures to glutamate, confirming that glu- 

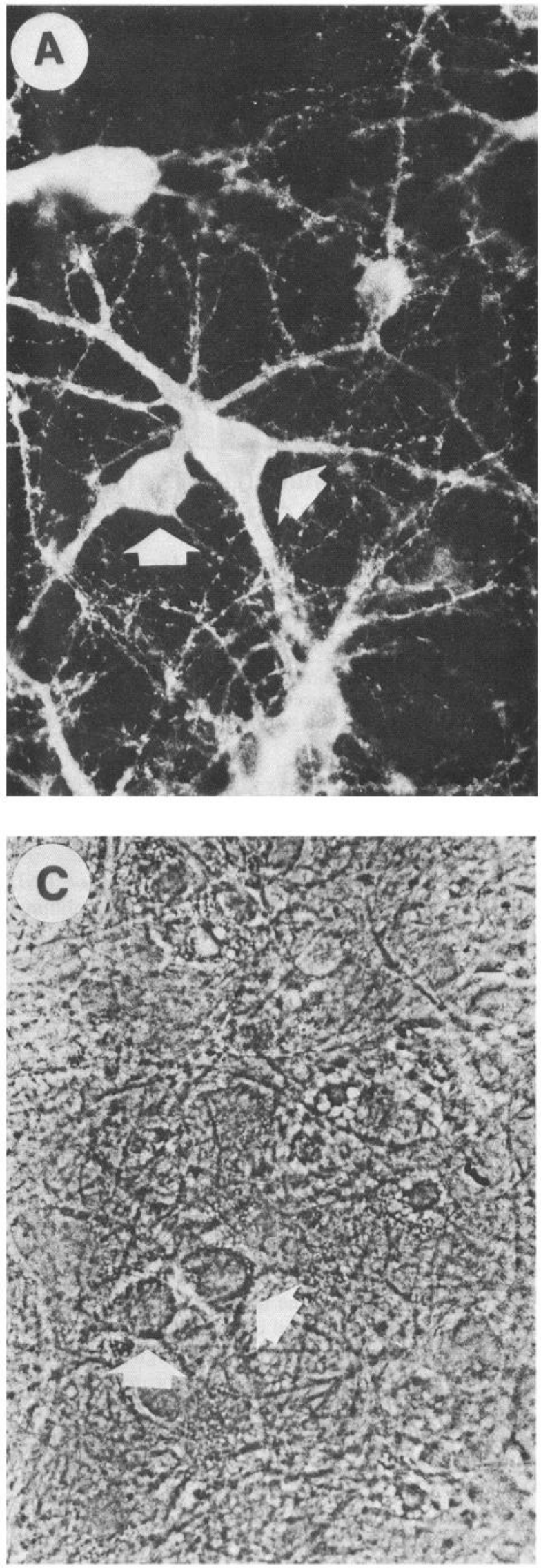
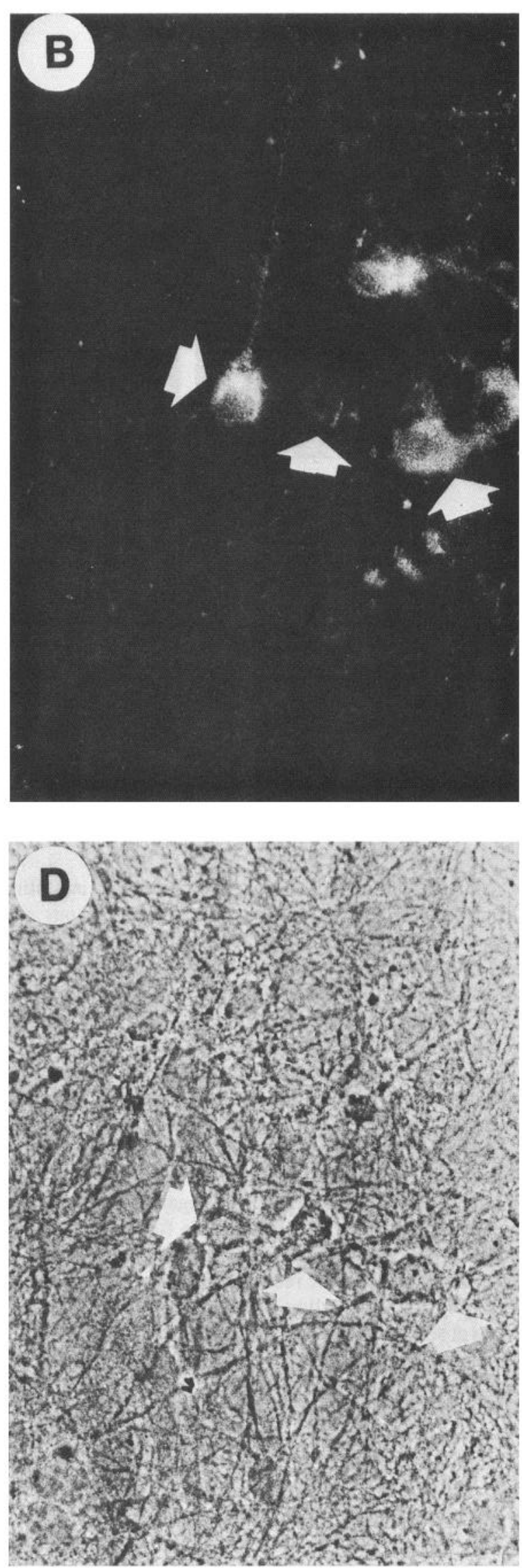

Figure 12. CaM kinase II immunocytochemistry in hippocampal neurons in cultures exposed to control $(A, C)$ or glutamate $(500 \mu \mathrm{M} ; B, D)$ for $10 \mathrm{~min}$ and immediately fixed with paraformaldehyde. Neurons were immunoreacted with a monoclonal $\mathrm{IgG}_{3}(1 \mathrm{C} 3-3 \mathrm{D} 6)$ directed against the beta 
tamate rapidly induced a significant inhibition of CaM kinase II activity following excitotoxic exposure. In addition, the decreased immunoreactivity observed in situ confirmed that measurement of neuronal kinase, relative to glial kinase, is affected by excitotoxic glutamate exposure.

\section{Discussion}

Primary hippocampal neuronal cultures were utilized to measure directly the effect of glutamate exposure on neuronal viability, modulation of $\left[\mathrm{Ca}^{2+}\right]_{i}$, and inhibition of CaM kinase II activity within the same preparation. Excitotoxic glutamate exposures that resulted in delayed neuronal cell death and prolonged $\left[\mathrm{Ca}^{2+}\right]_{i}$ transients also resulted in significant inhibition of $\mathrm{CaM}$ kinase II activity. The glutamate-induced inhibition of CaM kinase II activity was observed immediately following excitotoxic (10 min) glutamate exposure and was observed at all time points measured. Furthermore, the inhibition of CaM kinase II activity was dependent upon both the stimulation of the NMDA subtype of glutamate-gated channels and the presence of extracellular calcium, $\left[\mathrm{Ca}^{2+}\right]_{o}$. The results also confirm earlier reports of NMDA (Choi et al., 1988; Michaels and Rothman, 1990; Churn

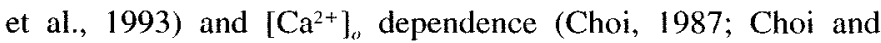
Hartley, 1993) of glutamate-induced neuronal cell death. In addition, the observations that conditions which result in delayed neuronal cell death also result in inhibition of CaM kinase II activity are consistent with the hypothesis that preservation of CaM kinase II activity is important for neuronal viability. These observations provide evidence that inhibition of CaM kinase II activity may be an important step in the cascade of events that ultimately result in delayed neuronal cell death.

Inhibition of CaM kinase II activity is an early and longlasting phenomenon in global forebrain ischemia (Churn et al., 1990a,b, 1992a; Zivin et al., 1991; Aronowski et al., 1993). Although proteolytic destruction of kinase subunits has been suggested in prolonged ischemia (Yamamoto et al., 1992), the inhibition of CaM kinase II in transient ischemia models has been shown to be due to a posttranslational modification of the enzyme which results in inhibition of enzymatic activity (Aronowski et al., 1992; Churn et al., 1992a). Since the inhibition observed after glutamate excitotoxicity was not due to enzymatic degradation of the kinase, it is reasonable to speculate that similar mechanisms that resulted in global forebrain-induced inhibition of CaM kinase II activity were active in glutamate excitotoxicity-induced CaM kinase II inhibition. Therefore, the primary neuronal culture model described in this report provides a powerful tool to characterize the excitotoxic inhibition of CaM kinase II and excitotoxicity-induced neuronal cell death.

Decreased immunoreactivity of CaM kinase II with a monoclonal antibody directed towards the $\beta$ subunit of the enzyme has been reported in whole animal ischemia (Churn et al., 1992a,b). In the gerbil ischemia model, the decreased immunoreactivity was not due to autophosphorylation (Churn et al., $1992 \mathrm{~b}$ ) or to destruction of the enzyme since when balanced for subunit staining the decreased immunoreactivity was still observed (Churn et al., 1992a,b). In addition, loss of immunoreactivity was observed only in neuronal populations that undergo delayed neuronal cell death, such as the pyramidal neurons of the hippocampus (Churn et al., 1992b). Thus, altered immunoreactivity was observed in neuronal populations that displayed delayed neuronal cell death, but not in populations that were insensitive to the effects of transient ischemia. The same antibody was utilized to establish the effect of glutamate toxicity on CaM kinase II immunoreactivity in hippocampal cultures. Excitotoxic glutamate exposure resulted in an immediate loss of immunoreactivity of CaM kinase II with the monoclonal antibody. The decreased immunoreactivity paralleled the decreased enzymatic activity observed in this model and was observed prior to neuronal cell death. In the gerbil model of ischemia, the hippocampal pyramidal neurons which were sensitive to ischemia are the same populations that lose immunoreactivity with kinase antibody (Churn et al., 1992b). In the hippocampal culture model of glutamate toxicity, the pyramidal neurons also lost immunoreactivity with the monoclonal antibody. Since pyramidal cells comprise approximately $30 \%$ of the neuronal population (Coulter et al., 1992), the resultant loss of immunoreactivity within these cells would explain the magnitude of loss of immunoreactivity that was apparently greater than the loss of enzyme activity. Thus, it is possible that CaM kinase II activity in the glutamate-sensitive pyramidal neurons may be reduced by almost $100 \%$ under cytotoxic conditions. Further study of the total neuronal population in which neuronal cells lose kinase immunoreactivity will be performed in future studies. Thus, excitotoxic glutamate exposure resulted in an analogous altered immunoreactivity of CaM kinase II as observed in the whole animal ischemia model (Onodera et al., 1990; Churn et al., 1992b). This observation suggests that excitotoxic glutamateinduced CaM kinase II inhibition occurred by similar mechanisms as that observed in whole animal models of ischemia.

Knowledge of the pharmacology of glutamate induced neurotoxicity is important for our understanding of neurotoxicity that occurs in vivo. Previous reports have demonstrated that selective blockade of the NMDA receptor channels during glutamate exposure resulted in preservation of neuronal viability (Choi et al., 1988; Michaels and Rothman, 1990; Churn et al., 1993). In the present study, pharmacologic blockage of the NMDA channel with MK-801, but not the AMPA glutamate receptor channels (CNQX) preserved CaM kinase II activity, In addition, specific NMDA agonists resulted in a similar inhibition of CaM kinase II activity as did glutamate application. The results support the hypothesis that excitotoxic activation of NMDA receptor channels results in inhibition of CaM kinase II activity. The same NMDA receptor activation results in a delayed neuronal cell death. Thus, excitotoxic NMDA receptor activation results in inhibition of CaM kinase II activity and delayed neuronal cell death.

CaM kinase II is highly enriched in neurons and is especially concentrated in the synaptic regions (Kennedy et al., 1983a; Goldenring et al., 1984b; Kelly et al., 1984). Therefore, CaM kinase II may regulate important neuronal processes involved in neurotransmission. Activation of NMDA receptors has been shown to activate CaM kinase $\mathrm{II}$ in a calcium-dependent manner (Fukunaga et al., 1992). The NMDA-dependent kinase activation results in the production of a calcium-independent form of the

$(60 \mathrm{kDa})$ subunit of CaM kinase II (see Materials and Methods). A, Control cultures showing neuronal specific immunofluorescence with IC3-3D6. $B$, Glutamate-treated cultures demonstrating a loss of immunoreactivity with the anti-CaM kinase II antibody. $C$, Phase micrograph showing the same neurons in $A$ from control-treated culture. $D$, Phase micrograph showing the same neurons in $B$ from glutamate-treated culture. 
kinase that may contribute to the increased neuronal excitability obscrved in LTP. Data from this study demonstrate that pathological stimulation of NMDA receptors resulted in inhibition of CaM kinase II activity that preceded calcium-dependent, delayed neuronal death. Since no modulation of $\mathrm{Ca}^{2+}$-independent activity was observed following glutamate treatment, the present report suggests that pathological neuronal excitation resulted in a total inhibition of CaM kinase II activity. The chronic inhibition of CaM kinase II activity may underlie some of the NMDAinduced pathological mechanisms that result in delayed neuronal death or other neuropathologies such as epilepsy and seizure activity.

It has been demonstrated that glutamate toxicity is dependent upon influx of extracellular calcium (Choi, 1987; Choi et al., 1988; Michaels and Rothman, 1990; Choi and Hartley, 1993). To characterize whether influx of extracellular $\mathrm{Ca}^{2+}$ is occurring in our system, confocal microscopic quantitation of Indo-1 fluorescence was performed. Both glutamate and $\mathrm{KCl}$ exposures resulted in significant elevation of $\left[\mathrm{Ca}^{2+}\right]_{i}$. However, $\left[\mathrm{Ca}^{2+}\right]_{i}$ remained elevated following the removal of the glutamate stimulus but returned to baseline levels upon removal of $\mathrm{KCl}$ solution. This prolonged calcium transient observed in glutamate-treated neurons has been proposed to be a causal factor in glutamateinduced, delayed neuronal cell death (Choi, 1987; Connor et al., 1988; Glaum et al., 1990). Calcium entry was site specific for mediating cell death, since increases in $\left[\mathrm{Ca}^{2+}\right]$, by NMDA receptor activation and not by depolarization-gated calcium channels causes delayed neuronal cell death, and extended neuronal depolarization (Sombati et al., 1991, Coulter et al., 1992). The results of the present study demonstrated that the calcium-induced CaM kinase II inhibition was also site specific, since calcium entry through NMDA receptor activation, but not voltagegated calcium channels caused kinase inhibition. Thus, the increase in $\left[\mathrm{Ca}^{2+}\right]_{i}$ induced by excitotoxic glutamate treatment may alter select $\mathrm{Ca}^{2+}$-regulated cellular processes modulated by NMDA receptor activation that are important for neuronal viability. The role of the site specific increases in $\left[\mathrm{Ca}^{2+}\right]_{i}$ in causing the inhibition of CaM kinase II activity needs to be further elucidated.

It has been shown that removal of calcium from the incubation medium during toxic glutamate exposure prevented neurotoxicity (Choi, 1987; Michaels and Rothman, 1990). Therefore, we tested whether removal of calcium from the extracellular medium would protect CaM kinase II activity. Removal of extracellular calcium during glutamate exposure blocked the excitotoxic inhibition of CaM kinase II activity. The finding that removal of extracellular calcium protects CaM kinase II activity parallels two other observations of neurotoxicity. Choi et al. (1987) have shown that removal of extracellular calcium prevents the calcium-dependent, delayed (calcium-dependent) neuronal cell death. In addition, Coulter et al., (1992) has shown that removal of extracellular calcium will also prevent the induction of END (Coulter et al., 1992). The observation that removal of extracellular calcium during excitotoxic glutamate exposure also protected CaM kinase II activity may lead to insight into the intracellular events which control both the development of END and progress to eventual neuronal degeneration.

Modulation of CaM kinase II activity has been demonstrated in models of neuronal plasticity such as LTP (Lisman, 1985; Lisman and Goldring, 1988; Malenka et al., 1989; Silva et al., 1992a,b), kindling (Wasterlain and Farber, 1984; Goldenring et al., 1986) and also in models of neuronal cell death such as status epilepticus (Perlin et al., 1992) and stroke (Churn et al., 1990b, 1992a; Zivin et al., 1991; Aronowski et al., 1993). In stroke, early and long term inhibition of CaM kinase II activity suggests that inhibition of this major neuronal enzyme may be important in the excitotoxic events which culminate in neuronal cell death. In addition, immunohistochemical studies showed that loss of CaM kinase II immunoreactivity occurred in the same neuronal population that was sensitive to ischemia (Onodera et al., 1990; Churn et al., 1992b). This report describes analogous findings of CaM kinase II inhibition to those observed in whole animal models. The inhibition of CaM kinase II activity observed in both ischemia and excitotoxic preparations indicates that the cell culture model may be a powerful tool to decipher the intracellular mechanisms and the role of CaM kinase II inhibition in modulating the excitotoxic events that result in delayed neuronal death.

\section{References}

Abele AE, Scholz KP, Scholz WK, Miller RJ (1990) Excitotoxicity induced by cnhanced cxcitatory ncurotransmission in cultured hippocampal pyramidal neurons. Neuron 4:413-419.

Abney ER, Bartlett PP, Raff MC (1981) Astrocytes, ependymal cells, and oligodendrocytes develop on schedule in dissociated cell cultures of embryonic rat brain. Dev Biol 83:301-310.

Amador M, Dani JA (1991) Protein kinase inhibitor, H-7, directly affects $N$-methyl-D-aspartate receptor channels. Neurosci Lett 124:251255.

Aronowski J, Grotta JC, Waxham MN (1992) Ischemia-induced translocation of $\mathrm{Ca}^{2+} /$ calmodulin-dependent protein kinase II: possible role in neuronal damage. $\mathrm{J}$ Neurochem 58:1743-1753.

Aronowski J, Waxham MN, Grotta JC (1993) Neuronal protection and preservation of calcium/calmodulin-dependent protein kinase II and protein kinase $\mathrm{C}$ activity by dextrorphan treatment in global ischemia. J Cereb Blood Flow Mctab 13:550-557.

Babcock-Atkinson E, Norenberg MD, Norenberg LO, Neary JT (1989) Calcium/calmodulin-dependent protein kinase activity in primary astrocyte cultures. Glia 2:112-118.

Banker GA, Cowan WM (1977) Further observations on hippocampal neurons in dispersed cell cultures. J Comp Neurol 187:469-494.

Baskys A, Bernstein NK, Barolet AW, Carlen PL (1990) NMDA and quisqualate reduce a $\mathrm{Ca}^{2+}$-dependent $\mathrm{K}^{+}$current by a protein kinasemediated mechanism. Neurosci Lett 112:76-81.

Burke BE, DeLorenzo RJ (1981) $\mathrm{Ca}^{2+}$ - and calmodulin-stimulated endogenous phosphorylation of neurotubulin. Proc Natl Acad Sci USA 78:991-995

Caroni P, Carafoli $\mathrm{E}$ (1983) The regulation of the $\mathrm{NA}^{+}-\mathrm{Ca}^{2}$ exchanger of heart sarcolemma. Eur J Biochem 132:451-460.

Choi DW (1987) Ionic dependence of glutamate neurotoxicity. J Neurosci 7:369-379.

Choi DW (1988) Calcium-mediated neurotoxicity: relationship to specific channel types and role in ischemic damage. Trends Neurosci 11: $465-469$.

Choi DW (1992) Bench to bedside: the glutamate connection. Science 258:241-243.

Choi DW, Hartley DM (1993) Calcium and glutamate-induced cortical neuronal death. Res Publ Assoc Res Nerv Ment Dis 71:23-34.

Choi DW, Rothman SM (1990) The role of glutamate neurotoxicity in hypoxic-ischemic neuronal death. Annu Rev Neurosci 13:171-182.

Choi DW, Maulucci Gedde M, Kriegstein AR (1987) Glutamate neurotoxicity in cortical cell culture. J Neurosei 7:357-368.

Choi DW, Koh JY, Peters S (1988) Pharmacology of glutamate neurotoxicity in cortical cell culture: attenuation by NMD $\Lambda$ antagonists. J Neurosci 8:185-196.

Churn SB, Taft WC, Billingsley MS, Blair RE, DeLorenzo RJ (1990a) Temperature modulation of ischenic neuronal death and inhibition of calcium/calmodulin-dependent protein kinase II in gerbils. Stroke 21: 1715-1721.

Churn SB, Taft WC, DeLorenzo RJ (I990b) Effects of ischemia on multifunctional calcium/calmodulin-dependent protein kinase type II in the gerbil. Stroke 21:III112-III116.

Churn SB, Taft WC, Billingsley MS, Sankaran B, DeLorenzo RJ 
(1992a) Global forebrain ischemia induces a post-translational modification of multifunctional calcium- and calmodulin-dependent kinase II. J Neurochem 59:1221-1232.

Churn SB, Yaghmai A, Povlishock J, Rafiq A, DeLorenzo RJ (1992b) Global forebrain ischemia results in decreased immunoreactivity of calcium/calmodulin-dependent protein kinase II. J Cereb Blood Flow Metab 12:784-793.

Churn SB, Sombati S, Taft WC, DeLorenzo RJ (1993) Excitotoxicity affects membrane potential and calmodulin kinase II activity in cultured rat cortical neurons. Stroke 24:271-278.

Connor JA, Tseng HY (1988) Measurement of intracellular $\mathrm{Ca}^{2+}$ in cerebellar Purkinje neurons in culture: resting distribution and response to glutamate. Brain Res Bu11 21:353-361.

Connor JA, Wadman WJ, Hockberger PE, Wong WKS (1988) Sustained dendritic gradients of $\mathrm{Ca}^{2+}$ induced by excitatory amino acids in C $\triangle 1$ hippocampal neurons. Science 240:649-653.

Coulter DA, Sombati S, DeLorenzo RJ (1992) Electrophysiology of glutamate neurotoxicity in vitro: induction of a calcium-dependent extended neuronal depolarization. J Neurophysiol 68:362-373.

DeLorenzo RJ (1981) The calmodulin hypothesis of neurotransmission. Cell Calcium 2:365-385.

DeLorenzo RJ (1983) Calcium-calmodulin protein phosphorylation in neuronal transmission: a molecular approach to neuronal excitability and anticonvulsant drug action. Adv Neurol 34:325-338.

DeLorenzo RJ, Gonzalez B, Goldenring J, Bowling A, Jacobson R (1982) $\mathrm{Ca}^{2+}$-calmodulin tubulin kinase system and its role in mediating the $\mathrm{Ca}^{2+}$ signal in brain. Prog Brain Res 56:257-286.

Erondu NE, Kennedy MB (1985) Regional distribution of type II calcium/calmodulin-dependent protein kinase in rat brain. $\mathbf{J}$ Neurosci 5:3270-3277.

Fukunaga K, Soderling TR, Miyamoto E (1992) Activation of $\mathrm{Ca}^{2+} /$ calmodulin-dependent protein kinase II and protein kinase $\mathrm{C}$ by glutamate in cultured rat hippocampal neurons. J Biol Chem 267:2252722533.

Glaum SR, Scholz WK, Miller RJ (1990) Acute- and long-term glutamate-mediated regulation of $\left[\mathrm{Ca}^{++}\right]_{i}$ in rat hippocampal pyramidal neurons in vitro. J Pharmacol Exp Ther 253:1293-1302.

Goldenring JR, Gonzalez B, McGuire JS Jr, DeLorenzo RJ (1983) Purification and characterization of a calmodulin-dependent kinase from rat brain cytosol able to phosphorylate tubulin and microtubule-associated protcins. J Biol Chem 258:12632-12640.

Goldenring JR, Casanova JE, DeLorenzo RJ (1984a) Tubulin-associated calmodulin-dependent kinase: evidence for an endogenous complex of tubulin with a calcium-calmodulin-dependent kinase. J Neurochem 43:1669-1679.

Goldenring JR, McGuire JS Jr, DeLorenzo RJ (1984b) Identification of the major postsynaptic density protein as homologous with the major calmodulin-binding subunit of a calmodulin-dependent protein kinase. J Neurochem 42:1077-1084.

Goldenring JR, Wasterlain CG, Oestreicher AB, de Graan PN, Farber DB, Glaser G, DeLorenzo RJ (1986) Kindling induces a long-lasting change in the activity of a hippocampal membrane calmodulin dependent protein kinase system. Brain Res 377:47-53.

Hanson PI, Schulman H (1992) Inhibitory autophosphorylation of multifunctional $\mathrm{Ca}^{21} / \mathrm{calmodulin-dependent} \mathrm{protein} \mathrm{kinase} \mathrm{analyzed} \mathrm{by}$ site-directed mutagenesis. J Biol Chem 267:17216-17224.

Hartley DM, Kurth MC, Bjerkness L, Weiss JH, Choi DW (1993) Glutamate receptor-induced ${ }^{45} \mathrm{Ca}^{2+}$ accumulation in cortical cell culture correlates with subsequent neuronal degeneration. J Neurosci 13: 1993-2000.

Hashimoto Y, Soderling TR (1987) Calcium calmodulin-dependent protein kinase II and calcium phospholipid-dependent protein kinase activities in rat tissues assayed with a synthetic peptide. Arch Biochem Biophys 252:418-425.

Jameson L, Frey T, Zeeberg B, Dalldorf F, Caplow M (1980) Inhibition of microtubule assembly by phosphorylation of microtubule-associated proteins. Biochemistry 19:2472-2479.

Kelly PT, McGuinness TL, Greengard P (1984) Evidence that the major post synaptic density protein is a component of calcium/calmodulin protein kinase. Proc Natl Acad Sci USA 81:945-949.

Kennedy MB, Bennett MK, Erondu NE (1983a) Biochemical and immunochemical evidence that the "major postsynaptic density protein" is a subunit of a calmodulin-dependent protein kinase. Proc Natl Acad Sci USA 80:7357-7361.

Kennedy MB, McGuinness T, Greengard P (1983b) A calcium/cal- modulin-dependent protein kinase from mammalian brain that phosphorylates synapsin I: partial purification and characterization. J Neurosci 3:818-831.

Koh JY, Choi DW (1991) Selective blockade of non-NMDA receptors does not block rapidly triggered glutamate-induced neuronal death. Brain Res 548:318-321.

Lai Y, Nairn AC, Greengard P (1986) Autophosphorylation reversibly regulates the calcium/calmodulin-dependent protein kinase II. Proc Natl Acad Sci 83:4253-4257.

Lisman J (1985) A mechanism for memory storage insensitive to molecular turnover: a bistable autophosphorylating kinase. Proc Natl Acad Sci USA 82:3055-3057.

Lisman J, Goldring M (1988) Evaluation of a model of long-term memory based on the properties of the $\mathrm{Ca}^{2+} /$ calmodulin-dependent protein kinase. J Physiol (Lond) 83:187-197.

Llinas R, McGuinness TL, Lconard CS, Sugimori M, Grecngard P (1985) Intra-terminal injection of synapsin I or calcium/calmodulindependent kinase II alters neurotransmitter release at the squid giant synapse. Proc Natl Acad Sci USA 82:3035-3039.

Machu TK, Firestone JA, Browning MD (1993) $\mathrm{Ca}^{2+} /$ calmodulin-dependent protein kinase II and protein kinase $\mathrm{C}$ phosphorylate a synthetic peptide corresponding to a sequence that is specific for the gamma $2 \mathrm{~L}$ subunit of the $\mathrm{GABA}_{\mathrm{A}}$ receptor. J Neurochem 61:375377.

Malenka RC, Kauer JA, Perkel DJ, Mauk MD, Kelly PT, Nicoll RA, Waxham MN (1989) An essential role for postsynaptic calmodulin and protein kinase activity in long term potentiation. Nature 340: 554-557.

McGlade-McGulloh E, Yamamoto H, Tan S-E, Brickey D, Soderling TR (1993) Phosphorylation and regulation of glutamate receptors by calcium/calmodulin-dependent protein kinase II. Nature 362:640642.

Michaels RL, Rothman SM (1990) Glutamate neurotoxicity in vitro: antagonist pharmacology and intracellular calcium concentrations. J Neurosci 10:283-292.

Murphy SN, Miller RJ (1988) A glutamate receptor regulates $\mathrm{Ca}^{2+}$ mobilization in hippocampal neurons. Proc Natl Acad Sci USA 85 $8737-8741$.

Onodera H, Hara H, Kogure K, Fukunaga K, Ohta Y, Miyamoto E (1990) $\mathrm{Ca}^{2+} /$ calmodulin-dependent protein kinase II immunoreactivity in the rat hippocampus after forebrain ischemia. Neurosci Lett 113:134-138

Ouimet CC, McGuiness TL, Greengard P (1984) Immunocytochemical localization of calcium/calmodulin-dependent kinase II in rat brain Proc Natl Acad Sci USA 81:5604-5608.

Patton BL, Molloy SS, Kennedy MB (1993) Autophosphorylation of type II CaM kinase in hippocampal neurons: localization of phosphoand dephosphokinase with complementary phosphorylation site-specific antibodies. Mol Biol Cell 4:159-172

Perlin JB, Churn SB, Lothman EW, DeLorenzo RJ (1992) Loss of type II calcium/calmodulin-dependent kinase activity correlates with stages of development of electrographic seizures in status epilepticus in rat. Epilepsy Res 11:111-118.

Portzehl H, Caldwell PC, Reugg JC (1964) The dependence of contraction and relaxation of muscle fibers from the crab Maia squimado on the internal concentration of free calcium ions. Biochim Biophys Acta 79:581-591.

Rothman SM (1986) Glutamate and anoxic neuronal death in vitro. Adv Exp Med Biol 203:687-695.

Sakakibara M, Alkon DL. DeLorenzo RJ, Goldenring JR, Neary JT, Heldman E (1986) Modulation of calcium-mediated inactivation of ionic currents by calcium/calmodulin-dependent protein kinase II. Biophys J 50:319-327.

Schulman H (1989) The multifunctional calcium/calmodulin-dependent protein kinase. In: Advances in second messenger and phosphoprotein research (Greengard P, Robinson GA, eds), pp 39-112. New York: Raven.

Shields SM, Ingebritsen TS, Kelly PT (1985) Identification of protein phosphatase $l$ in synaptic junctions: dephosphorylation of endogenous calmodulin-dependent kinase and synapse-enriched phosphoproteins. J Neurosci 5:3414-3422.

Silva AJ, Paylor R, Wehner JM, Tonegawa S (1992a) Impaired spatial learning in alpha-calcium-calmodulin kinase II mutant mice [see comments]. Science 257:206-211.

Silva AJ, Stevens CF, Tonegawa S, Wang Y (1992b) Deficient hippo- 
campal long-term potentiation in alpha-calcium-calmodulin kinase II mutant mice [see comments]. Science 257:201-206.

Sombati S, Coulter DA, DeLorenzo RJ (1991) Neurotoxic activation of glutamate receptors induces an extended neuronal depolarization in cultured hippocampal neurons. Brain Res 566:316-319.

Taft WC, Tennes Rees KA, Blair RE, Clifton GL, DeLorenzo RJ (1988) Cerebral ischemia decreases endogenous calcium-dependent protein phosphorylation in gerbil brain. Brain Res 447:159-163.

Wadman WJ, Connor JA (1992) Persisting modification of dendritic calcium by excitatory amino acid stimulation in isolated CA1 neurons. Neuroscience 48:293-305.

Wasterlain CG, Farber DB (1984) Kindling alters the calcium/calmo- dulin-dependent phosphorylation of synaptic plasma membrane proteins in rat hippocampus. Proc Natl Acad Sci USA 81:1253-1257.

Yamamoto H, Fukunaga K, Goto S, Tanaka E, Miyamoto E (1985) Calcium, calmodulin-dependent regulation of microtubule formation via phosphorylation of microtubule-associated protein 2, tau factor, and tubulin and comparison with the cyclic AMP-dependent phosphorylation. J Neurochem 44:759-768.

Yamamoto H, Fukunaga K, Lee K, Soderling TR (1992). Ischemiainduced loss of brain calcium/calmodulin-dependent protein kinase II. J Neurochem 58:1110-1117.

Zivin JA, Kochhar A, Saitoh T (1991) Protein phosphorylation during ischemia. Stroke [Suppl] 21:III117-III121. 